\title{
Unsaturated Polyester Resin for Specialty Applications
}

\author{
Bharat Dholakiya
}

Additional information is available at the end of the chapter

http://dx.doi.org/10.5772/48479

\section{Introduction}

Polymers are substances whose molecules consist of a large number of units of a few types: the units themselves, consisting of a number of atoms, are usually referred to as the segments of the polymer. In the polymerization of a mixture of two monomers, the structure of each macromolecule contains units of both monomers. Such a polymer is called copolymer and the process of its synthesis is called copolymerization.

Polyesters [1-3] are one of the most versatile synthetic copolymers. Polyesters are produced in high volume that exceeds 30 billion pounds a year worldwide [3]. They are widely used commercially as fibres, plastics, composites and for coatings applications too [4-6]. They are heterochain macromolecules that possess carboxylate ester groups as an integral component of their polymer backbones. Polyesters have received a great deal of attention since the early work of Carothers, who initiated study on many step-growth polymerizations [7]. His work involved A-B $\omega$-hydroxy acids, the polymerization of certain lactones and the esterification of A-A linear diols with B-B terminal aliphatic dicarboxylic acids. The resulting copolymers were of low molecular weight $(8,000-10,000 \mathrm{~g} / \mathrm{mol})$, hard, crystalline solids and susceptible to conversion from the molten state to filaments which could be stretched below their melting point with an ultimate increase in strength.

Carothers worked with aliphatic straight-chain polyesters, which were soluble in organic liquids, low melting and had poor resistance to hydrolysis. These polyesters were not used as textile fibres [5]. The extension of these concepts later led to the discovery of nylon-6,6 in 1935 and Whinfield and Dickson developed poly(ethylene terephthalate) (PET) in 1941[8]. A partially aromatic organic structure was necessary to increase melting temperature $\left(\mathrm{T}_{\mathrm{m}}\right)$ above $250^{\circ} \mathrm{C}$. A large number of polyester structures have found use in industry today which displays a wide variety of properties and applications. More detailed discussion may be found in a number of excellent books and reviews [3-4\&6]. 


\subsection{Types of polyester resin}

\subsubsection{Saturated polyester resin [9]}

These are the reaction products of dibasic acids or dibasic acid chlorides with diols and largely used in textile industries e.g. Polyethylene terephthalate.
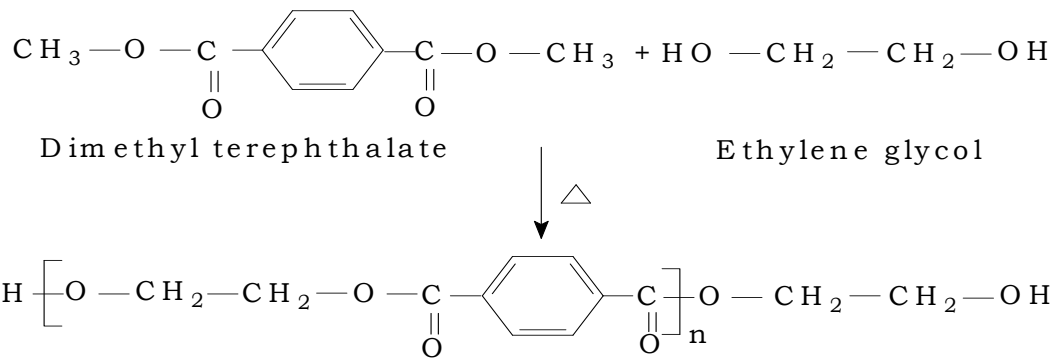

\subsubsection{Alkyd resin [9]}

Alkyds are the reaction products of polyhydric alcohols with fatty acids followed by reaction with dibasic acids. They are largely used in paint and printing ink industries [10-14].

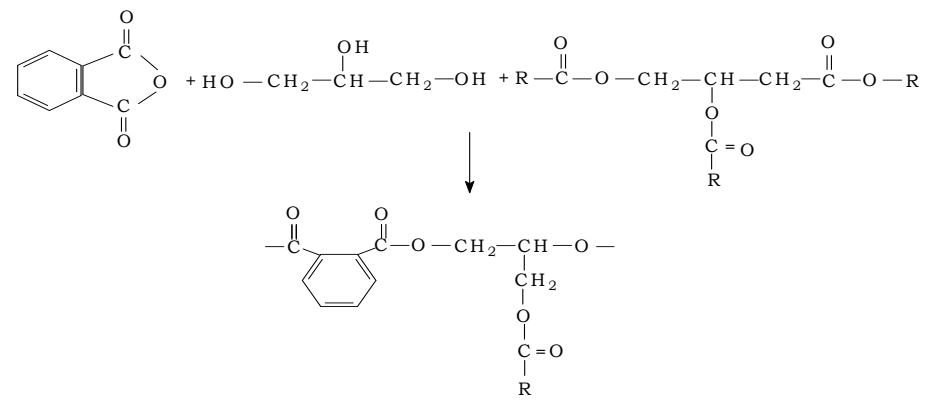

\subsubsection{Vinyl ester resin [4]}

Vinyl ester resins are becoming increasingly important in new industrial applications such as coating, printed circuit boards, metal foil laminates, building materials, automotive parts, rigid foams and fibre reinforced composites [15-19]. A conventional vinyl ester resin can be prepared by end capping various epoxy resins with unsaturated mono-carboxylic acid [2022]. They combine the excellent mechanical, chemical and solvent resistance properties of epoxy resins with the properties found in the unsaturated polyester resins. The cured vinyl ester resin has physical properties superior to cured conventional polyester resin, particularly corrosion resistance. Vinyl ester resins were developed in the late 1950's and early 1960 's i.e. just after II $^{\text {nd }}$ world war. The resins were prepared by reacting glycidyl acrylate and glycidyl methacrylate with bisphenol-A. These resins are very reactive and 
have very short life. A general structure of vinyl ester obtained by reacting epoxy resin with acrylic acid is as shown below.

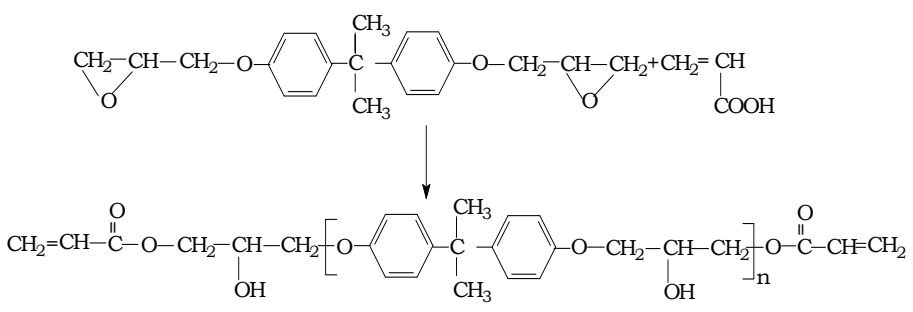

\subsubsection{Unsaturated polyester resin}

Unsaturated polyester resins are the condensation products of unsaturated acids or anhydrides and diols with/without diacids. The unsaturation present in this type of polyesters provides a site for subsequent cross-linking [23-24]. Since 1930, unsaturated polyester resins have been used remarkably for wide range of applications making them a thermosetting system of major importance [25-26]. These resins are compounded with varied fillers, reinforcements and cured by using free radical initiators to yield thermoset articles having a wide range of chemical and mechanical properties depending upon the choice of diacids, diols, cross- linking agents, initiators and other additives [27]. This versatility in the properties of the final thermoset product associated with comparatively low cost has renewed the interest in these resins as an important matrix material for wide range of applications. In 1929, Arvin and Carothers [28] developed unsaturated polyester resins from maleic acid and ethylene glycol reacted at temperature $175^{\circ}-185^{\circ} \mathrm{C}$. Ford Motor Co. Ltd.[29] synthesized unsaturated polyester resin by reacting maleic anhydride and phthalic anhydride with propylene glycol at $100^{\circ} \mathrm{C}$ and then at $250^{\circ} \mathrm{C}$ till the acid number diminished to the value less than 50 (mg of $\mathrm{KOH}$ per gm of sample). Corrado and his assistants [30] synthesized low viscosity unsaturated polyester resins by reacting maleic anhydride, phthalic anhydride and dipropylene glycol at $200^{\circ} \mathrm{C}$. Ochsenbein and Olliver [31] synthesized storage stable unsaturated polyester resin by reacting maleic anhydride, propylene glycol and dipropylene glycol at $185^{\circ} \mathrm{C}$ under inert atmosphere. General purpose unsaturated polyester resins were prepared by using maleic anhydride, phthalic anhydride and propylene glycol with the molar ratio of phthalic anhydride: maleic anhydride ranging from 1:2 to 2:1[32-33]. For thermoset products, the resultant resin was blended with styrene for cross-linking and small amount of peroxide as initiator. These types of resins are useful in making trays, shower stalls, boats, swimming pool, water tanks etc.

Acrylic modified unsaturated polyester resin having good cracking resistance, flexibility and thixotropic property were synthesized using 65 parts 0.15:1.0:0.3:0.7 molar ratio of dicyclopentadiene: fumaric acid: ethylene glycol : diethylene glycol copolymer and 35 parts of 2-hydroxy ethylmethacrylate [34]. Chemical resistant thermosetting unsaturated polyester resins for laminates having low content of volatile organic components were 
prepared from isophthalic acid, maleic anhydride and propylene glycol with $35 \%$ styrene as reactive diluents [35]. Unsaturated polyester resin prepared from isophthalic acid, maleic anhydride and neopentyl glycol was mixed with dicyclopentadiene resin and styrene to give dielectric compound for electric machines [36]. The effect of styrene content on nonexponential and non-Arrhenius behaviour of the $\alpha$-relaxation of cured unsaturated polyester resin was investigated by dynamic mechanical analysis [37].

A review on recent research progress in modification methods of unsaturated polyester resin, with an emphasis on the toughening and reinforcement, flame proofing, improving heat resistance and resistance to environmental medium, reducing contraction percentage of cured unsaturated polyester resin and air drying properties was done by Q. Jun-min et. al. [38]. The research development on unsaturated polyester resins during the year 2000-2001 was reviewed with references [39]. The review on the development trends in the production of unsaturated polyester resins was done by Penezek [40]. Literature survey reveals that there are many reports about the synthesis and modification methods of unsaturated polyester resin [41-49].

\subsection{Fire resistant polyester resin [48]}

Fire resistant polyester resins can be prepared by using halogenated dibasic acids e.g. tetrachlorophthalic anhydride(I), tetrabromophthalic anhydride(II) [49], dibromoneopentyl glycol (III) [50] or tetrabromo bisphenol-A (IV) [51] in place of phthalic anhydride or propylene glycol. Fire resistance of polyester resins can be further improved by blending with flame retardant additives such as triphenyl phosphate and antimony trioxide [52]. Such types of resins are generally used in fume hoods, electrical equipments, building panels and navy boats.

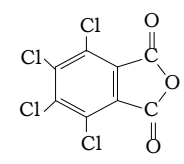

(I)

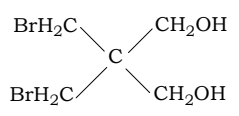

(III)

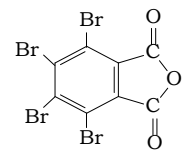

(II)

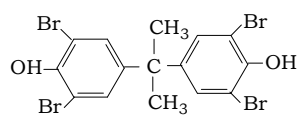

(IV)

\subsection{Electrical resistant polyester resin [48]}

Electrical resistant polyester resins can be prepared by using dibasic acids e.g. isophthalic acid, maleic anhydride and neopentyl glycol [53] or tetrabromobisphenol-A [51] in place of phthalic anhydride or propylene glycol. Electrical resistance of polyester resins can be further improved by blending with various additives such as antimony trioxide [54], kaolin [55], mica [56] and calcium carbonate [57]. Such types of resins are generally used in printed circuit board, electrical appliances and electronic equipments. 


\subsection{Low styrene emission polyester resin}

The unsaturated polyester normally blended with styrene to a reactive resin solution. The styrene acts both as a cross-linking agent and as a viscosity reducer so that the resin can be processed. In conventional unsaturated polyesters the styrene content varies between 35$45 \mathrm{wt} \%$. The styrene monomer in the unsaturated polyester resin is an environmental and occupational health problem due to evaporation and emissions, which occur during the processing of the resin. During the end of the 1980.s the environmental problems caused by styrene emission from the processing of unsaturated polyesters were debated a lot in the society, especially in the Nordic countries. The producers of unsaturated polyesters started therefore to search actively for alternatives to styrene and started to develop additives inhibiting styrene emission.

\section{Unsaturated polyester based fire resistance composites}

\subsection{Introduction}

The fire behavior of materials is an important parameter to be considered for the safety of individuals and it must be taken into account at the beginning of equipment development. The use of composite materials for building equipment is becoming increasingly important and it has been clearly demonstrated by tests on structures that composite materials with an organic matrix behave well than traditional materials (woods in the naval area, aluminium in the aeronautic sector), in the case of a fire. In the naval sector, it is not the case that there are more fires on ships with composite structures than on ships with metallic structures. For several years the use of composites in interiors of cabin and even for structures is common in the aeronautic sector because of weight gains and there have not been more incidents observed on equipment due to the potentially greater fire risk [58-60]. Since many years, unsaturated polyester composites have been used in very varied technology fields as naval constructions, offshore applications, water piping, building construction and automotive applications. In spite of hydrolytic instability problems of these materials, mainly due to the fact of their pre-polymer ester functions [61-62], interest in unsaturated polyester resin comes from their low cost and easy processing. Due to their stable structure, they display good mechanical properties and furthermore, unsaturated polyester resin has good thermal stability. However, the use of these materials is limited due to their poor fire performance. There are some solutions [63]. Survey of literature revels that there are many reports about the fire resistance behavior of the glass reinforced composites [64-88].

The aim of this work was to prepare halogen free fire resistance composites by using nontraditional fillers like fly ash, zinc borate and hydroxyapatite in combination with traditional filler antimony trioxide in different amounts in prepolymer polyester resin and study the thermal and the fire behavior with and without fillers in order to investigate the role played by fillers in the thermal and fire degradation reactions. 


\subsection{Synthesis of Unsaturated Polyester Resin (UPR-1)}

Unsaturated polyester resin (figure-1) was prepared in the present work using technique reported by T Sunemi Hidenari [89]. A mixture of $1.25 \mathrm{~mol}$ Propylene glycol (PG), $0.5 \mathrm{~mol}$ Phthalic anhydride (PA), $0.2 \%$ p- Toluene sulfonic acid (PTSA) and Xylene as solvent was charged in a three-neck reaction kettle equipped with stirrer, thermometer, nitrogen-gas introducing tube, separator and water condenser. The mixture was mechanically stirred and heated at $120^{\circ} \mathrm{C}$ under nitrogen gas stream. When reaction mass becomes clear, it was allowed to cool to $80^{\circ} \mathrm{C}$ and then $0.5 \mathrm{~mol}$ Maleic anhydride (MA) was added and continues heating at $150-200^{\circ} \mathrm{C}$ until an acid number of 20 was reached. During esterification reaction, water formed as by product and was continuously removed from the reaction mass as it inhibits the rate of reaction. The Xylene was completely distilled out and reaction product was allowed to cool. When the temperature reached to $160^{\circ} \mathrm{C}, 20 \mathrm{mg}$ of hydroquinone was added as inhibitor and when resin temperature dropped below the boiling point of reactive diluent (i.e. Styrene), the polyester resin were mixed with styrene by 35 weight percent of resin [90]. The polymer obtained was characterized Gel Permeation chromatography (GPC) and IR spectroscopy.
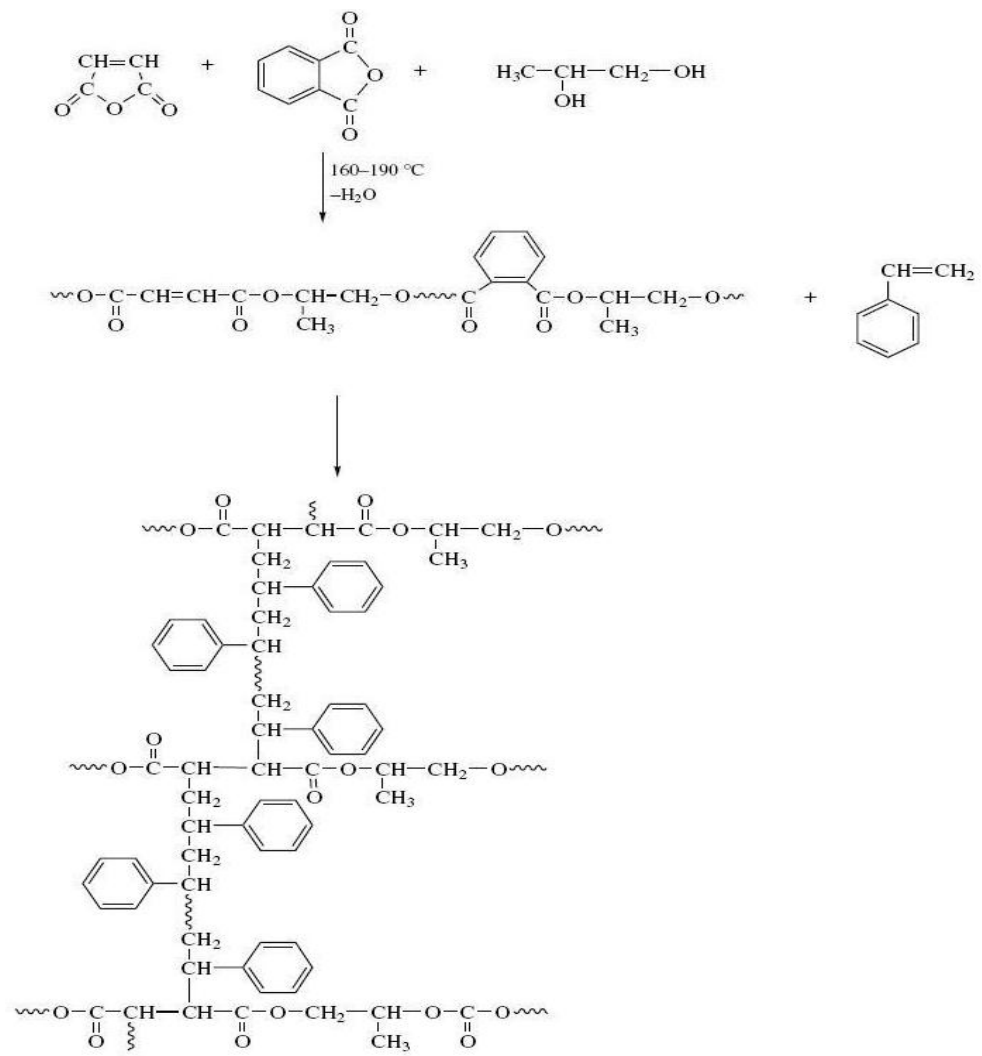

Figure 1. Polyester Resin (UPR-1) Scheme with Cross linking [92] 


\subsection{Fire resistance formulation and composite preparation}

\subsubsection{Fillers for fire resistance formulation}

Some non-traditional filler like hydroxyapatite, zinc borate and fly ash were used in combination with traditional filler antimony trioxide for fire resistance formulation. The details about fillers are given as below:

\subsubsection{Hydroxyapatite}

The formula of hydroxyapatite is $\mathrm{Ca}_{10}\left(\mathrm{PO}_{4}\right)_{6}(\mathrm{OH})_{2}$. It forms part of the crystallographic family of apatite, isomorphic compounds with the same hexagonal structure. Hydroxyapatite can be found in nature or synthesized by precipitation method using chemical reagents. It is also known as calcium phosphate. This compound is most commonly used for biomaterial and fire resistant applications. This compound can be physically blended in polymers to suppress, reduce, delay or modify the propagation of flame through polymeric materials. The fire retardant property of hydroxyapatite is due to the presence of phosphate. The technical specifications of hydroxyapatite used in this work are given as below:

1. $\mathrm{Ca} / \mathrm{P}$ molar ratio: 1.61-1.71.

2. Crystalline hydroxyapatite content: $95 \%$.

3. Grain size: $1500-2000$ mesh

4. Moisture: $1 \%$ max.

\subsubsection{Zinc borate}

Zinc borate, $2 \mathrm{ZnO}_{3} \mathrm{~B}_{2} \mathrm{O}_{3} 3.5 \mathrm{H}_{2} \mathrm{O}$, is a white crystal powder, which does not dissolve in water and other organic solvent but it does dissolve in hydrochloric and sulphuric acid. It has good thermal stability, lower density and good miscibility with most of the polymers. Zinc borate shows excellent fire resistance performance and can be therefore widely used in polymer, rubber, fibre, paint and ceramic industries. The technical specifications of zinc borate used in this work are given below:

1. $\mathrm{B}_{2} \mathrm{O}_{3}: 48 \%$,

2. $\mathrm{ZnO}: 37 \%$

3. Particle size: 1250 mesh -1850 mesh

4. Loss on ignition: $13.50-15.50 \%$

5. Moisture: $1.0 \%$ max.

\subsubsection{Fly ash}

Fly ash is the finely divided mineral residue resulting from the combustion of coal in electric generating plant. Fly ash consists of inorganic matter present in the coal that has been fused during coal combustion. This material is solidified while suspended in the exhaust gases and is collected from the exhaust gases by electrostatic precipitators and is usually of silt sizes $(0.074-0.005 \mathrm{~mm})$. Fly ash is a pozzolanic material and has been classified into two 
classes $\mathrm{F}$ and $\mathrm{C}$ based on the chemical composition of fly ash. In the present study class $\mathrm{C}$ fly ash was used. Class $\mathrm{C}$ fly ash is produced normally from lignite and sub-bituminous coals. The technical specifications of fly ash used in this work are given below:

1. Silicon dioxide $\left(\mathrm{SiO}_{2}\right)$ plus $\mathrm{Al}_{2} \mathrm{O}_{3}$ plus $\mathrm{Fe}_{2} \mathrm{O}_{3}: 55.0 \%$

2. Sulfur trioxide $\left(\mathrm{SO}_{3}\right): 5.0 \%$

3. Moisture content: $3.0 \%$ max.

4. Loss on ignition: $6.0 \%$

\subsubsection{Antimony trioxide}

The formula of antimony trioxide is $\mathrm{Sb}_{2} \mathrm{O}_{3}$. It is a solid white powder and is used mainly as fire retardant additive and as pigment. The substance comes in various grades, depending on particle size. The breakdown of particle size affects both physical properties and pigment property. The finer fraction is used for pigmentation. The flame-retardant property, however, is not affected by particle size. This property is based on antimony trioxide reacting in the event of fire with the surrounding material, with the result that a protective layer of various antimony compounds covers the combustible materials. Since the formation of these compounds consumes heat and because they are generally difficult to ignite, they protect the underlying material from ignition. The technical specifications of antimony trioxide used in this work are given as below:

1. Total antimony oxide content: $99.50 \%$

2. Bulk density: $0.3-1.0 \mathrm{gms} / \mathrm{cc}$

3. Average particle size: $1.1 \mu \mathrm{m}$

Fire resistance formulations were prepared by adding non-traditional fillers like fly ash, zinc borate and hydroxyapatite in combination with traditional filler antimony trioxide in different amounts (10 to $30 \mathrm{wt} \%$ ) in prepolymer polyester resin (table-1). Several combinations were tested to determine effects of each additive in the polymer formulations. Additives in different amount were mixed with prepolymer polyester resin in a round bottom flask equipped with high speed agitator. The resultant formulations were compounded with glass fibre as reinforcing materials and benzoyl peroxide as initiator for composite preparation. Composites were prepared by hand lay-up technique using about 50 weight percent of glass fibre and filler. After application of resin on glass fibre the composites were cured by compression moulding at 7 bar pressure and $120^{\circ} \mathrm{C}$ temperature for 30 minutes. Two percent benzoyl peroxide (BPO) was used as initiator. The composites obtained from fire resistance formulations were characterized by Limiting oxygen index, (LOI) according to ASTM D-2863 [91], thermo gravimetric analysis (TGA) and IR spectroscopy.

\subsection{Characterization}

Prepolymer polyester resin synthesized by above procedure was analyzed by GPC, FTIR and TGA. 


\begin{tabular}{|c|c|c|c|c|c|c|c|}
\hline \multirow{2}{*}{$\begin{array}{c}\text { Composite } \\
\text { code }\end{array}$} & $\begin{array}{c}\text { UPR-1 } \\
\text { Composition } \\
\text { in Wt } \%\end{array}$ & Reinforcement & \multicolumn{4}{|c|}{ Fillers in Wt \% } & $\begin{array}{c}\text { Limiting } \\
\text { in Wt } \%\end{array}$ \\
\cline { 5 - 7 } & & $\mathrm{Sb}_{2} \mathrm{O}_{3}$ & $\begin{array}{c}\text { Fly } \\
\text { Oxygen }\end{array}$ & $\begin{array}{c}\text { Hydroxy- } \\
\text { apatite }\end{array}$ & $\begin{array}{c}\text { Zinc } \\
\text { borate }\end{array}$ & $\begin{array}{c}\text { Index (LOI) } \\
\text { in \% }\end{array}$ \\
\hline FRC-1 & 100 & 100 & - & - & - & - & 21 \\
\hline FRC-2 & 100 & 70 & 30 & - & - & - & 25 \\
\hline FRC-3 & 100 & 70 & 20 & 10 & - & - & 27 \\
\hline FRC-4 & 100 & 70 & 10 & 20 & - & - & 29 \\
\hline FRC-5 & 100 & 70 & - & 30 & - & - & 31 \\
\hline FRC-6 & 100 & 70 & 20 & - & 10 & - & 28 \\
\hline FRC-7 & 100 & 70 & 10 & - & 20 & - & 30 \\
\hline FRC-8 & 100 & 70 & - & - & 30 & - & 32 \\
\hline FRC-9 & 100 & 70 & 20 & - & - & 10 & 32 \\
\hline FRC-10 & 100 & 70 & 10 & - & - & 20 & 34 \\
\hline FRC-11 & 100 & 70 & - & - & - & 30 & 37 \\
\hline
\end{tabular}

* FRC=Fire resistance composites of UPR-1

Table 1. Fire Resistance Formulation and LOI [92].

\subsubsection{Gel Permeation Chromatography (GPC)}

GPC is one of the most powerful and versatile analytical technique available for understanding and predicting polymer performance. It is the only proven technique for characterizing a polymer by its complete molecular weight distribution. GPC of polyester resin was done by using Perkin Elmer 200 GPC instrument. The HPLC grade Tetrahydrofuran(THF) was used as a mobile phase at a flow rate of $1.0 \mathrm{ml} / \mathrm{min}$. The GPC system was equipped with two ultrastyragel columns packed with styrene-DVB copolymers of $10^{3}$ and $10^{6} \mathrm{~A}^{0}$ porosity connected in series to cover an exclusion limit of 200 to $10 \times 10^{6}$. Refractive Index detector was used with internal temperature of $35^{\circ} \mathrm{C}$ for peak detection. The GPC system was calibrated with eight different polystyrene standards having molecular weight ranging from 2000 to $2.5 \times 10^{6}$. The number average $\left(\mathrm{Mn}_{\mathrm{n}}\right)$ of polyester resin sample is 1554, weight average $\left(\mathrm{M}_{\mathrm{w}}\right)$ is 3576 and polydispersity $\left(\mathrm{M}_{\mathrm{w}} / \mathrm{Mn}_{n}\right)$ is 2.301. Gel permeation chromatography of polyester resin is shown in figure -2 .

\subsubsection{Spectral analysis of polyester resin}

An IR spectrum of prepolymer polyester resin is shown in figure-3. A Nicolet Impact 400D FT-IR Spectrophotometer was employed for the measurements. The spectrum was run by applying resin sample on $\mathrm{KBr}$ cell covering the range of frequencies from $4000-400 \mathrm{~cm}^{-1}$ with scanning period of 20 seconds. The crushed powder sample $(2-3 \mathrm{mg})$ in the form of a pellet was prepared by mixing with dry $\mathrm{KBr}(1 \mathrm{~g})$. The spectrophotometer was set at $100 \%$ transmittance with pure $\mathrm{KBr}$ pellet. A strong absorption band at $755 \mathrm{~cm}^{-1}$ and a weak band at $1004 \mathrm{~cm}^{-1}$ can be attributed to $-\mathrm{C}-\mathrm{H}$ bending arising from 1 and 3 position in benzene ring and $-\mathrm{C}=\mathrm{CH}$ bending arising from isomerisation of maleic anhydride to fumarate during 
polymerization. A broad-spectrum absorption bend at $1145 \mathrm{~cm}^{-1}$ confirms the presence of $\mathrm{C}-\mathrm{O}-\mathrm{C}$ - of ester linkage. A strong absorption peak appearing at $1306 \mathrm{~cm}^{-1}$ was assigned to $\mathrm{C}=\mathrm{C}-$ group of polyester. A medium absorption band at $1461 \mathrm{~cm}^{-1}$ can be attributed to $-\mathrm{C}-\mathrm{H}$ bending. The presence of $-\mathrm{C}=\mathrm{O}$ and symmetric $-\mathrm{CH}$ stretching was confirmed by the presence of strong bend at $1736 \mathrm{~cm}^{-1}$ and $2985 \mathrm{~cm}^{-1}$ respectively. The band at $1736 \mathrm{~cm}^{-1}$ confirms the presence of $-\mathrm{C}=\mathrm{O}$ ester group and also confirms the formation of polyester resin. In addition to this, disappearance of anhydride peak at $1755 \mathrm{~cm}^{-1}$ in maleic anhydride \& phthalic anhydride and hydroxyl peak at $1375 \mathrm{~cm}^{-1}$ proplyene glycol confirms the formation of polyester.

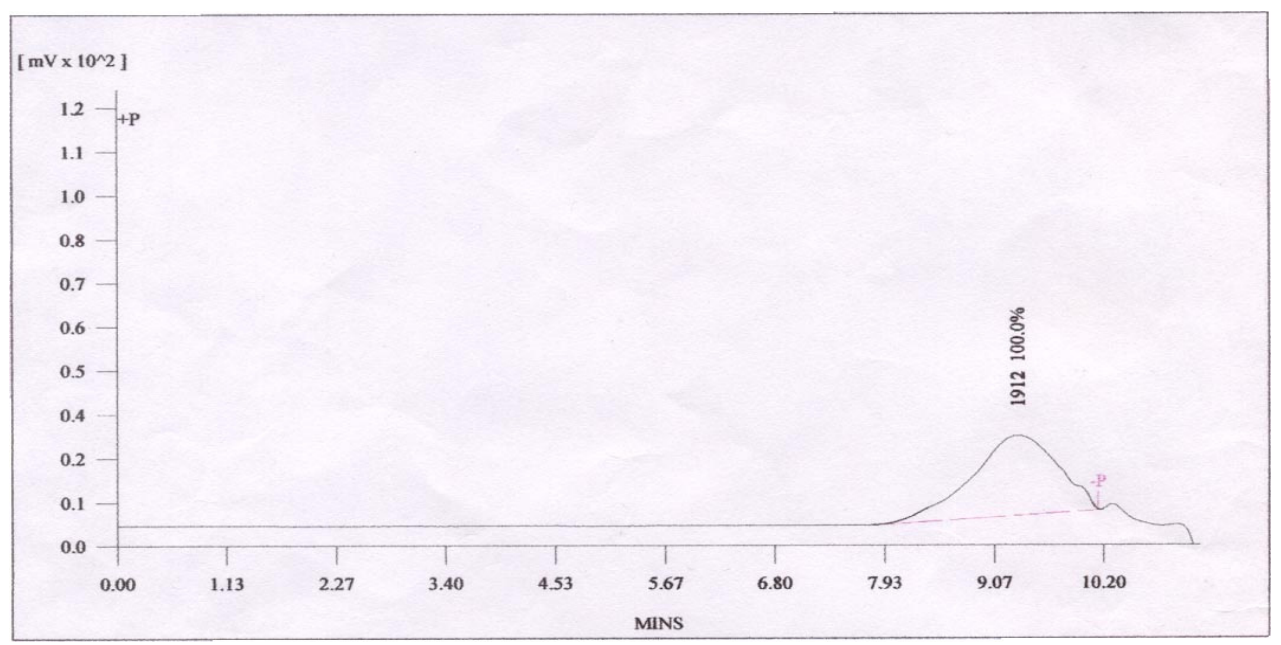

Figure 2. GPC of Polyester Resin

An IR spectrum of cured polyester resin is shown in figure-4. The band at around $2985 \mathrm{~cm}^{-1}$ became sharper and bands due to $-\mathrm{CH}=\mathrm{CH}$ - group almost disappears in composite and a new sharp band at $1447 \mathrm{~cm}^{-1}$ becomes visible in the IR spectrum of composite. This indicates the presence of alkane group, which clearly can be attribute to participation of $-\mathrm{CH}=\mathrm{CH}$ group in curing process and conversion of this group to alkane during cross linking process.

\subsubsection{Thermogravimetric analysis (TGA)}

TGA of the cured composites was carried out on TA Instruments, USA model 5000/2960. This instrument measures the weight loss as well as the rate of weight loss of a material continuously as a function of increase in temperature. The present study concerns the percentage weight loss of the material at different temperature at a heating rate of $10^{\circ} \mathrm{C} / \mathrm{min}$. The sample for analysis was kept in an oven at $35^{\circ} \mathrm{C}$ under vacuum overnight. The cured sample (about 8 to $12 \mathrm{mg}$ ) was placed in the sample container and suspended on the quartz rod in an atmosphere of nitrogen gas. The weight of the sample was noted on the TGA balance. The whole assembly was introduced into the furnace and the experiment started by heating the system at constant and definite rate throughout the experiment. Simultaneous 
change in weight was recorded automatically with the time while temperature was increased at a known uniform rate $\left(10^{\circ} \mathrm{C} / \mathrm{min}\right)$. The experiment was stopped when no further change in weight could be observed on further heating. Proper knowledge of the thermal stability of polymers is essential for their appropriate applications [93-95]. The thermal behaviour of polymers with reference to their thermal stability is of paramount importance.

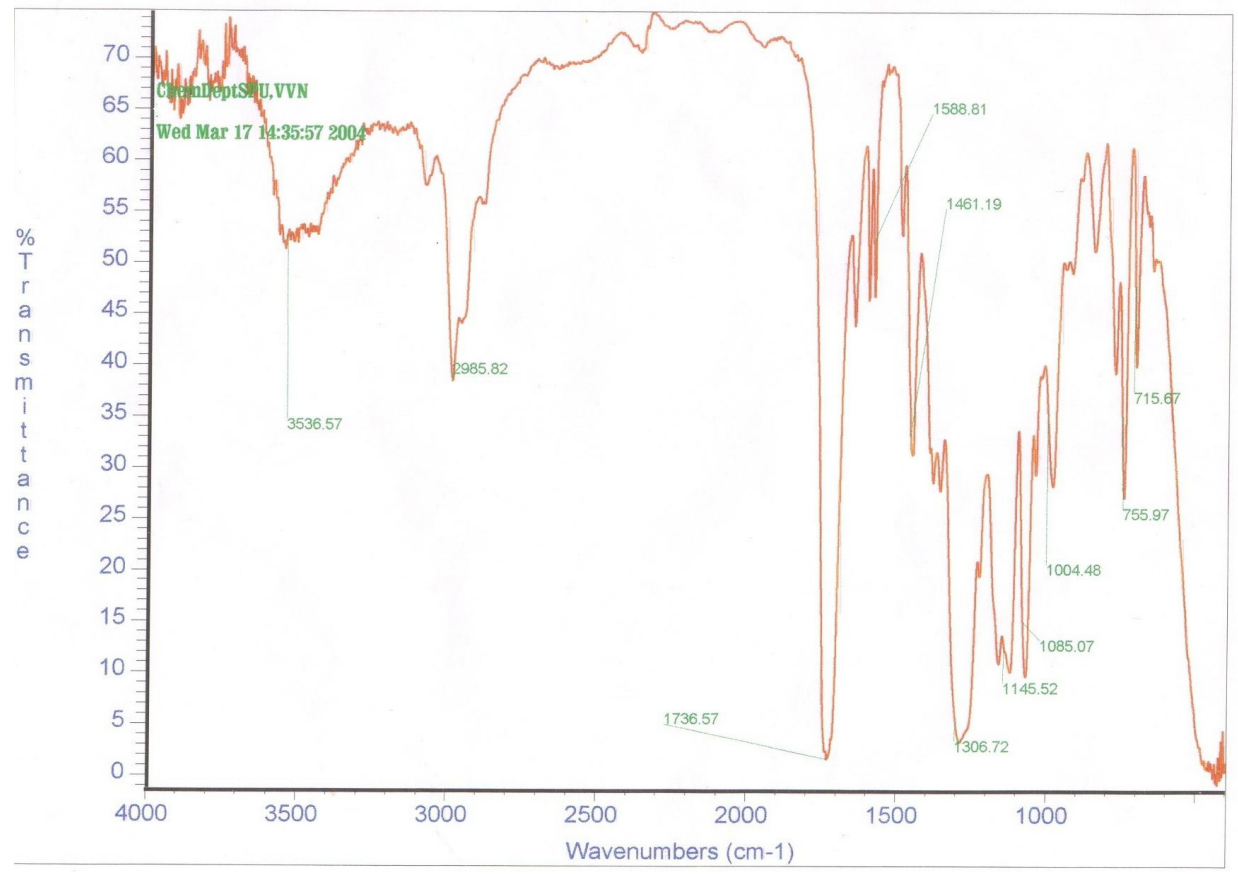

Figure 3. IR Spectra of UPR-1

TGA thermograms of all the composites indicate a similar decomposition pattern of two steps degradation. The first step can be assigned to degradation of resin part and the second one to that of filler part. The initial decomposition in almost all composites start at around $200^{\circ} \mathrm{C}$ with only 3-7 \% loss which clearly shows very good thermal stability of these composites up to $200^{\circ} \mathrm{C}$. In unfilled composite (figure-5) loss of weight at 100, 200, 300, 400 and $450{ }^{\circ} \mathrm{C}$ is $-3.09,-11.37,-34.71,-82.60$ and $-83.60 \%$ respectively. In filled composite (figure-6) loss of weight at 100, 200, 300, 400 and $450{ }^{\circ} \mathrm{C}$ is $-0.96,-10.30,-28.58,-65.00$ and $66.02 \%$ respectively. Filled composites show very good thermal stability than unfilled composites.

\subsection{Fire resistance properties of composites}

In this work, fire behaviour of composites was evaluated. Many procedures exist to evaluate fire behaviour of the composite materials [96-97].The key fire resistance properties of interest for polymers to be used in fire resistance applications are ease of ignition, flame 
spread, ease of extinction, smoke obscuration, smoke toxicity, heat release rate and limiting oxygen index. In the present study limiting oxygen index (ASTM D-2863) was determined to characterize the composites.

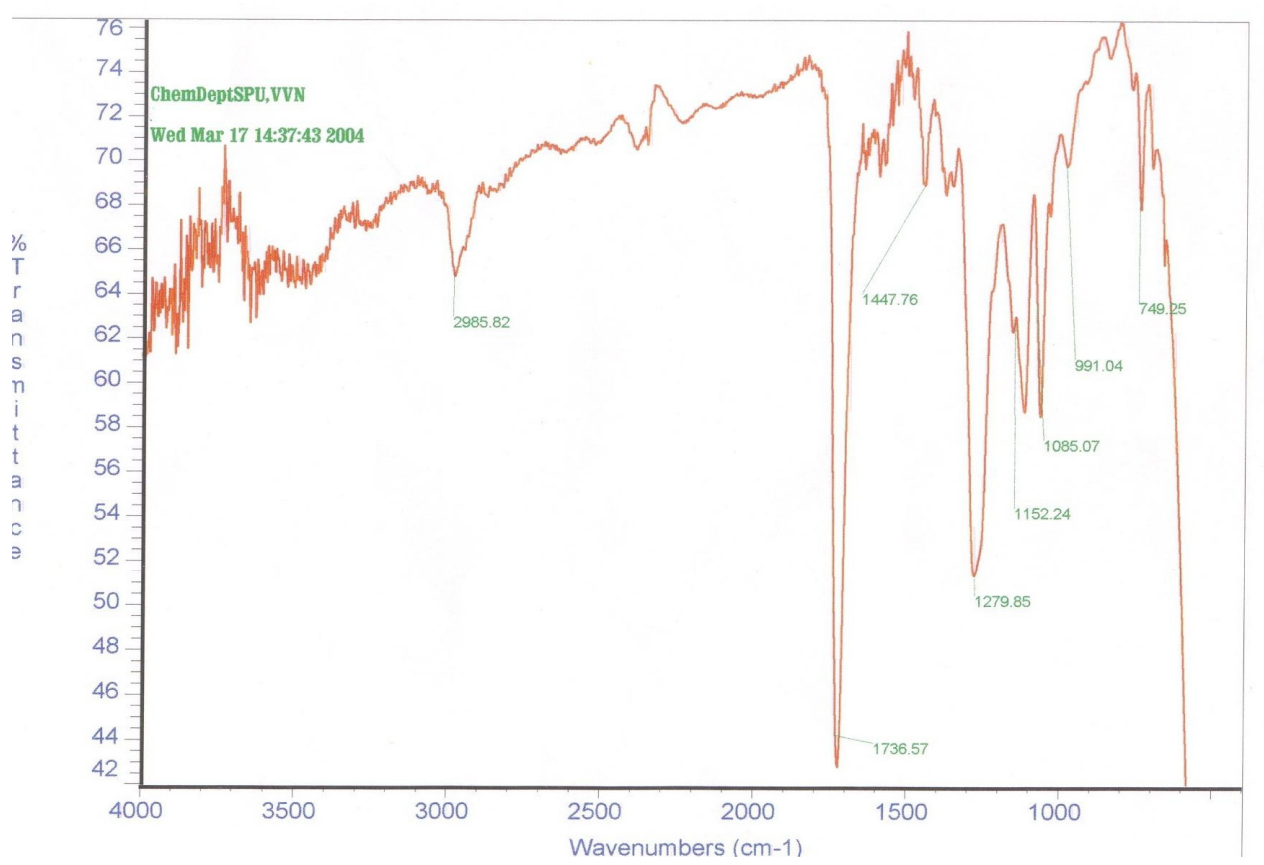

Figure 4. IR Spectra of FRC-1

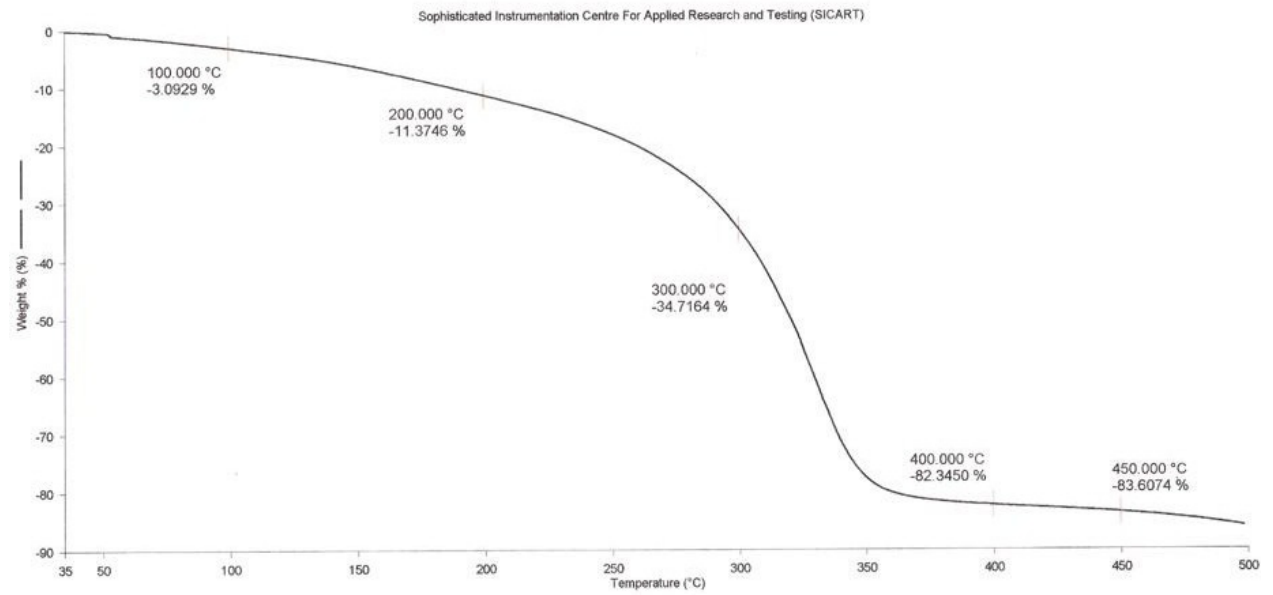

Figure 5. Thermogram of FRC-1 


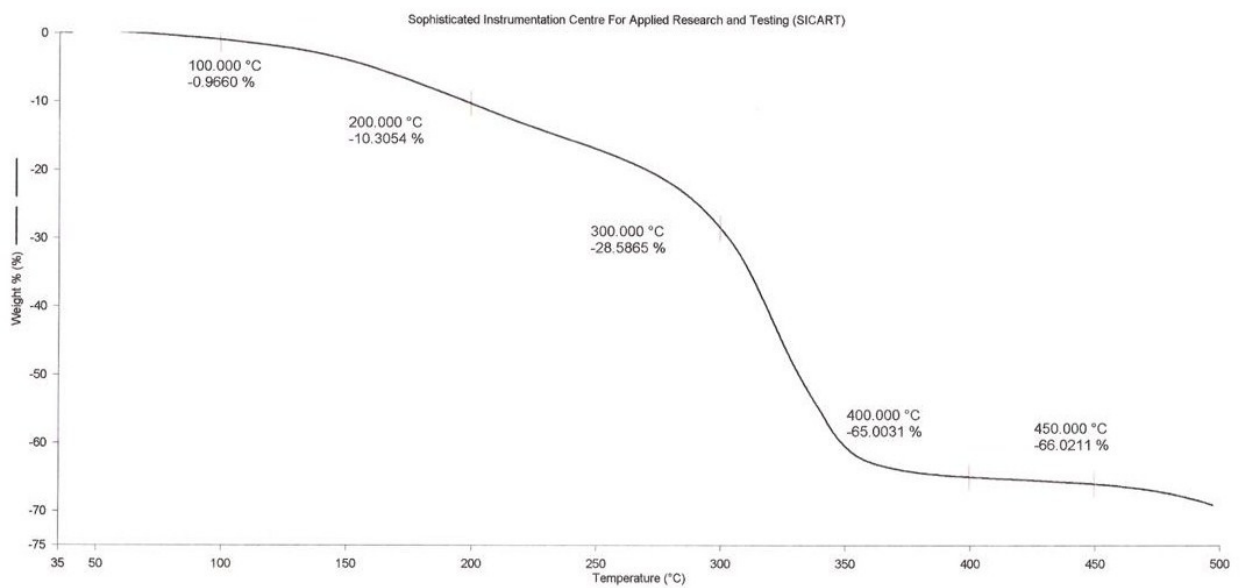

Figure 6. Thermogram of FRC-5

\subsubsection{Limiting Oxygen Index (LOI) ASTM D-2863 [91]}

Fennimore and Martin developed this method [98]. LOI is defined as measure of minimum amount of oxygen in an environment $\left(\mathrm{O}_{2}+\mathrm{N}_{2}\right)$ necessary to initiate and support the burning (flame) under specified conditions. ASTM D2863 is a method to determine the minimum concentration of oxygen in an oxygen/nitrogen mixture that will support a burning of test specimen. The specimen used for LOI test having size150 mm length, $10 \mathrm{~mm}$ wide and 4 $\mathrm{mm}$ thick. The apparatus used for LOI was Stanton Redcroft FTA flammability unit. The test sample is positioned vertically in a glass chimney and an oxygen/nitrogen environment is established with a flow from the bottom of the chimney. The top edge of the test sample is ignited and the oxygen concentration in the flow is decreased until the flame is no longer supported. Oxygen Index is calculated from the final oxygen concentrations tested. This is very simple and advantageous method for assessing fire resistance of polymers. The critical amount of oxygen was measured. LOI is expressed in percentage as:

$$
\mathrm{LOI}=\frac{\left[\mathrm{O}_{2}\right]}{\left[\mathrm{O}_{2}\right]+\left[\mathrm{N}_{2}\right]} \times 100
$$

Table-1 represents limiting oxygen index of filled and unfilled composites. In the present study values of limiting oxygen index of filled composites are in the range of 25-37. In practice material is often called the self extinguish materials if LOI is greater than 26 [99]. Thus the results of present study are in good agreement with the reported values. The results clearly indicate that the composites of present study can be used in all fire resistance applications. Composites prepared using fillers give better fire resistance than unfilled composites and also there is increase in fire resistance with increase in amount of filler. 


\subsection{Mechanical properties of fire resistance composites}

Mechanical properties measured in this study include Izod impact strength, Rockwell Hardness and Flexural strength.

\subsubsection{Izod impact strength}

The impact properties of the polymeric materials are directly related to the overall toughness of the material. The objective of the Izod impact test is to measure the relative susceptibility of a standard test specimen to the pendulum type impact load. The results are expressed in terms of kinetic energy consumed by the pendulum in order to break the specimen. A study of Izod impact strength was carried out in terms of resistance to breakage under high velocity impact conditions, according to ASTM D-256 [100].

Zwick model No. 8900 Impact Machine was used for the present study. For the measurement, a specimen was cut from the fabricated composite $\left(6.4 \times 1.27 \mathrm{~cm}^{2}\right)$ and V notched $(2.5 \mathrm{~mm})$ at the middle. The test specimen was clamped into position so that notched end of the specimen remained facing the striking edge of pendulum. The impact test indicates the energy to break standard test specimen of specified size under the stipulated conditions of specimen mounting and pendulum velocity at impact. All the measurements were carried out at room temperature.

\subsubsection{Rockwell hardness}

Hardness of a material is defined as the resistance to deformation, particularly permanent deformation, indentation or scratching. The Rockwell hardness test measures the net increase in depth impression as the load on an indentor is increased from a fixed minor to a major load and then returned to minor load. Rockwell Hardness study was carried out at room temperature according to standard method of testing ASTM D-785 [101].

In the present study, Rockwell hardness tester model RAS/Saroj Engg. Udyog Pvt. Ltd., Jaysingpur was used. Load of 100kgf was applied for each measurement. The specimen with parallel flat surfaces was placed on the avail of the apparatus and minor load (10kgf) was applied by lowering the steel ball onto the surface of the specimen. The dial was adjusted to zero on the scale under minor load and the major load (100kgf) was immediately applied by releasing the trip lever. After 15 second the major load was removed and the specimen was allowed to recover for 15 second. Rockwell hardness was read directly on the dial.

\subsubsection{Flexural strength}

It is one of the most important mechanical properties of interest for any comparison of rigid materials or modulus of rupture. Flexural strength is the ability of the material to withstand bending forces applied perpendicular to its longitudinal axis. The test specimens were conditioned in accordance with the ASTM D 790 [102].

A Dutron's Tensile Tester Model No. 130 was used in the present study. For the measurement, a strip of the dimensions $8.0 \times 1.25 \mathrm{~cm}^{2}$ was cut from the composites. It suited 
the gauge length of $7.5 \mathrm{~cm}$ i.e. the experiment was carried out a distance between two jaws to be $7.5 \mathrm{~cm}$ apart. The results were recorded with the chart speed of $2 \mathrm{~mm} / \mathrm{min}$ at room temperature. The test was initiated by applying the load to the specimen at the specified crosshead rate. The deflection was measured by gauge under the specimen in contact with it in the centre of the support span. Table-2 represents Izod impact strength, Rockwell hardness and Flexural strength.

\begin{tabular}{|c|c|c|c|}
\hline Composite code & $\begin{array}{c}\text { Izod Impact in Jcm- } \\
1\end{array}$ & Flexural Strength in MPa & Rockwell Hardness(M) \\
\hline FRC-1 & 5.09 & 238.85 & 59 \\
\hline FRC-2 & 4.15 & 230.85 & 57 \\
\hline FRC-3 & 5.00 & 238.75 & 59 \\
\hline FRC-4 & 4.00 & 230.15 & 57 \\
\hline FRC-5 & 3.50 & 225.00 & 50 \\
\hline FRC-6 & 7.00 & 240.00 & 60 \\
\hline FRC-7 & 10.05 & 245.85 & 62 \\
\hline FRC-8 & 11.50 & 247.90 & 64 \\
\hline FRC-9 & 7.25 & 242.00 & 61 \\
\hline FRC-10 & 10.10 & 246.15 & 63 \\
\hline FRC-11 & 11.80 & 247.90 & 66 \\
\hline
\end{tabular}

Table 2. Mechanical Properties of Fire resistance Composites [92]

The mechanical properties of composites improve remarkably with increase in the filler content except in antimony trioxide and fly ash. Increase in mechanical properties with increase in filler content is due to the reinforcement action provided by the filler particles to the polymer matrix [103-104]. Composites prepared using non-traditional fillers in combination with traditional filler gives better performance than unfilled composites and also there is increase in mechanical properties with increase in amount of fillers. Antimony trioxide gives poor results compared to other fillers and also mechanical performance decreases with increase in amount. For antimony trioxide and fly ash best results obtained for 20:10\% weight of antimony trioxide to fly ash in composites.

The results also revealed that the fire retardancy of the polyester based composites can be improved by using non traditional fillers like zinc borate, hydroxyapatite and fly ash. They have an advantage over a traditional filler antimony oxide to increase the fire retardancy without decreasing mechanical and thermal properties of the composites. There is however, considerable variation in the efficiency of these fillers. The adequacy of the fire resistance performance of these filled composites is dependent on both types of filler and incorporation level of the fillers. The use of antimony oxide and fly ash increases the fire resistance behaviour but there is decrease in mechanical properties and thermal stability. The optimum result obtained was with $30 \%$ zinc borate as filler with good improvement in fire resistance with considerable increases in mechanical properties and thermal stability. The use of such fillers can also solve the problems of toxic emissions of halogenated fire 
retardants and also it lowers the cost of polyester resin. The composites can be used for facade elements, dome light crowns, in the transportation sector, in the electrical industry, e.g. for cable distribution cupboards, for boats and shipbuilding, tanks, tubes, vessels and others electrical, electronic and electro technical applications like circuit breakers, switch board cabinets, automotive distributor caps, printed circuit board etc.

\section{Unsaturated polyester resin based electrical laminates}

\subsection{Introduction}

The unbeatable combination of characteristics such as ease of fabrication, low cost, light weight and excellent insulation properties have made composite materials to be one of the most desirable materials for electrical applications. The electrical properties of polymers are related to the behaviour of polymers as an electrical insulating material for the general interest. The purpose of electrical insulation may generally be described as the prevention of unwanted contacts between the electrical conductors at different potentials. A simple example such as two mounted terminals can usefully serve as an illustration. The insulation must maintain the separation under a wide variety of environmental hazards which include humidity, temperature, vibration, radiation, presence of gases, moisture and other contamination. It must be sufficiently strong physically to withstand the mechanical forces which may be exerted by the conductors and at the same time must prevent any significant flow of current between the conductors. No insulator is perfect, but what constituents a significant flow of current depends upon the application. A few micro amps in an electrical supply circuit would be negligible. In every case the current must be sufficiently small to eliminate secondary effects such as temperature rise, mechanical stress and electrochemical action.

The primary function of thermosetting plastics in electrical applications has been that of an insulator. Thermosetting plastics not act as effective insulators but also provide mechanical support for field carrying conductors. For this reason the mechanical properties of thermosetting plastics materials used as insulators become very important.

The use of glass-reinforced laminates in the field of dielectric materials has been of prime importance in the engineering materials. The choice of dielectric material depends upon its dielectric and other properties over a wide range of temperature and dielectric field frequencies. Investigation of dielectric properties is one of the most convenient and sensitive methods in studying structural property relationship of the glass reinforced for engineering purpose. Typical electrical application of fibre reinforced composite include terminals, connectors, industrial and house hold plugs, switches and printed circuit boards. Now a day unidirectional glass reinforced polymer composites have become a popular alternative to porcelain in the manufacture of high voltage insulators [105-127]. Several investigations on the effects of electrical properties and mineral fillers have been reported [128-129]. Survey of literature revels that there are some reports about the dielectric behaviour of the glass reinforced laminates [130-149]. The glass fibre reinforced laminates were studied for the electrical properties. There are several experimental and numerical procedures which can be used to evaluate the laminates in terms of electrical properties [150-165]. 
The aim of this work was to prepare electrical resistance composites and study the thermal and electrical behavior with and without electrical resistance additives in order to investigate the role played by additives in the electrical resistance. This chapter discusses the electrical resistance composites which were prepared by using unsaturated polyester resin and fillers (up to $40 \%$ by wt.) like mica, raw kaolin and surface treated kaolin with glass fiber and were evaluated for arc resistance, surface resistivity and volume resistivity according to ASTM standards.

\subsection{Synthesis of Unsaturated Polyester Resin (UPR-2)}

UPR was prepared in the present work using technique reported by T Sunemi Hidenari [89]. A mixture of $42.8 \mathrm{gm}$ (1.3 mol) Propylene glycol (PG), $35.96 \mathrm{gm}$ (0.5 mol) Isophthalic acid, 0.2 gm $(0.2 \%)$ p- Toluene sulfonic acid (PTSA) and Xylene as distillating solvent was charged in a three - neck reaction kettle equipped with stirrer, thermometer, nitrogen-gas introducing tube, Dean \& Stark apparatus and water condenser. The mixture was mechanically stirred and heated at $120^{\circ} \mathrm{C}$ under nitrogen gas stream and esterification was carried out while removing water formed by the reaction from the reaction system. When reaction mass becomes clear, it was allowed to cool. When the temperature was dropped to $80^{\circ} \mathrm{C}, 21.24 \mathrm{gm}(0.5 \mathrm{~mol})$ Maleic anhydride (MA) was added and continues heating at 200$225^{\circ} \mathrm{C}$ until an acid number of 25 were reached. The Xylene was completely distilled out and reaction product was allowed to cool. When the temperature reached to $160^{\circ} \mathrm{C}, 20 \mathrm{mg}$ of hydroquinone was added as inhibitor and when resin temperature dropped below the boiling point of reactive diluent (i.e. Styrene), the polyester resin was mixed with styrene by 35 weight percent by resin [90].

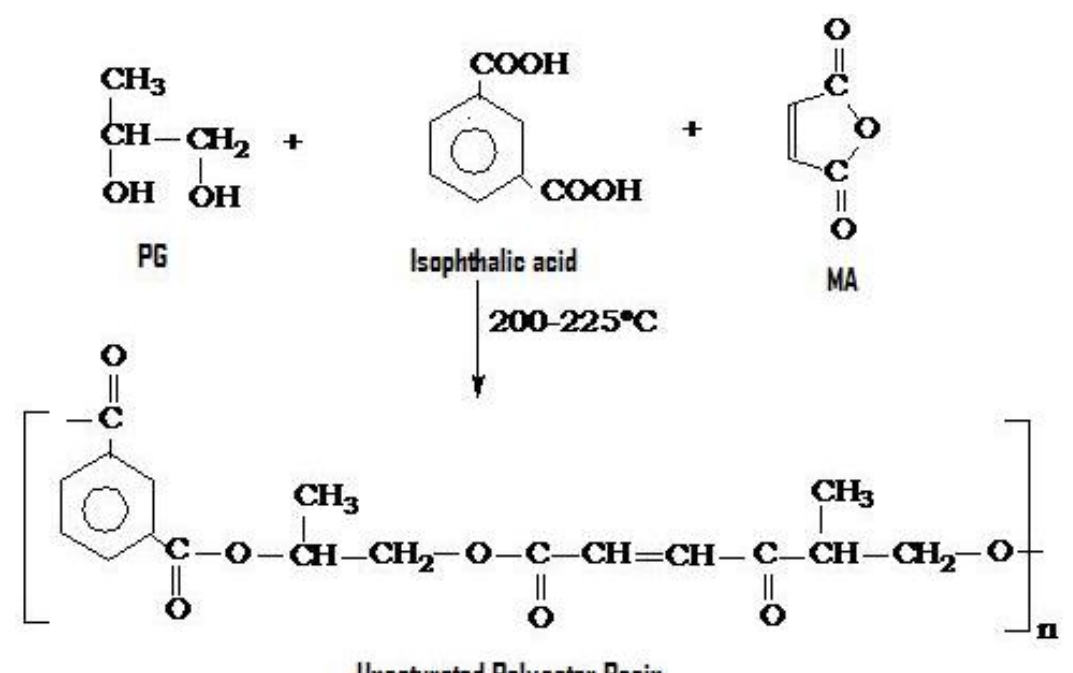

Figure 7. Reaction mechanism for UPR-2 


\subsection{Electrical resistance formulation and composite preparation}

\subsubsection{Fillers for electrical resistance formulation}

\subsubsection{Raw kaolin and surface treated kaolin}

Raw Kaolin is the common name for the mineral products comprised totally or substantially of the aluminium-silicate clay. Kaolin is an inherently fine particle-size, platy, chemically inert mineral. The work reported here seeks to improve the mechanical performance of composites by using surface treated kaolin. Surface treated kaolin was prepared by treating raw kaolin with surface active coupling agent. Commercially available silane was chosen as a surface active coupling agent because these materials have a history of applications in other polymer composites [166].

\subsubsection{Mica}

Mica is phyllosilicate mineral that have a layered or platy texture. The value of mica is in its unique physical properties. The crystalline structure of mica forms layers that can be split or delaminated into thin sheets. Mica is also chemically inert and is stable when exposed to electricity, light, moisture and extreme temperatures.

Electrical resistance formulations were prepared by adding various additives viz: raw kaolin, surface treated kaolin and mica in different amounts (10 to $40 \mathrm{wt} \%$ ) in unsaturated polyester resin (table-3). Several combinations were tested to determine effects of each additive in the polymer formulations. Additives in different amount were mixed with unsaturated polyester resin in a round bottom flask equipped with high speed agitator. The resultant formulations were compounded with glass fibre as reinforcing materials and benzoyl peroxide as curing catalyst for composite preparation. Composites were prepared by hand lay-up technique using about 50 weight percent of glass fibre and filler. After application of resin on glass fibre the composites were cured by compression moulding at 7 bar pressure and $120^{\circ} \mathrm{C}$ temperature for 30 minutes. Two percent benzoyl peroxide (BPO) was used as initiator. The composites obtained from electrical resistance formulations were characterized by surface resistivity, volume resistivity, arc resistance and IR.

\subsection{Characterization}

\subsubsection{Gel Permeation Chromatography (GPC)}

Gel permeation chromatography of unsaturated polyester resin is shown in figure-2. Gel permeation chromatography of polyester resin was done by using Perkin Elmer 200 GPC instrument. PL GEL mixed B type of column, Tetrahydrofuran as solvent and refractive index detector were used in this analysis. Volume of sample injected was $20 \mu \mathrm{l} / \mathrm{min}$. with retention time 9.309 minutes. The number average $\left(\mathrm{Mn}_{\mathrm{n}}\right)$ of polyester resin sample is 1554, weight average $\left(\mathrm{M}_{\mathrm{w}}\right)$ is 3576 and polydispersity $\left(\mathrm{M}_{\mathrm{w}} / \mathrm{M}_{\mathrm{n}}\right)$ is 2.301 . 


\begin{tabular}{|c|c|c|c|c|c|}
\hline \multirow{2}{*}{$\begin{array}{c}\text { Composite } \\
\text { Code }\end{array}$} & $\begin{array}{c}\text { UPR-2 Composition } \\
\text { in Wt } \%\end{array}$ & $\begin{array}{c}\text { Reinforcement } \\
\text { in Wt } \%\end{array}$ & \multicolumn{3}{|c|}{ Fillers in Wt $\%$} \\
\cline { 5 - 6 } & & & Mica & Raw Kaolin & $\begin{array}{c}\text { Surface Treated } \\
\text { Kaolin }\end{array}$ \\
\hline ERC-1 & 100 & 100 & - & - & - \\
\hline ERC-2 & 100 & 70 & $10 \%$ & - & - \\
\hline ERC-3 & 100 & 70 & $20 \%$ & - & - \\
\hline ERC-4 & 100 & 70 & $30 \%$ & - & - \\
\hline ERC-5 & 100 & 70 & - & $10 \%$ & - \\
\hline ERC-6 & 100 & 70 & - & $20 \%$ & - \\
\hline ERC-7 & 100 & 70 & - & $30 \%$ & - \\
\hline ERC-8 & 100 & 70 & - & $40 \%$ & - \\
\hline ERC-9 & 100 & 70 & - & - & $10 \%$ \\
\hline ERC-10 & 100 & 70 & - & - & $20 \%$ \\
\hline ERC-11 & 100 & 70 & - & - & $30 \%$ \\
\hline ERC-12 & 100 & 70 & - & - & $40 \%$ \\
\hline
\end{tabular}

ERC: Electrical Resistance Composites of UPR-2

Table 3. Electrical Resistance Composite Formulation

\subsubsection{Spectral analysis of polyester resin}

An IR spectrum of unsaturated polyester resin (UPR-2) is shown in figure-8. A Nicolet Impact 400D FT-IR Spectrophotometer was employed for the measurements. The spectrum was run by applying resin sample on $\mathrm{KBr}$ cell covering the range of frequencies from 4000 $400 \mathrm{~cm}^{-1}$. A strong absorption band at $742.54 \mathrm{~cm}^{-1}$ and a weak band at $1031.34 \mathrm{~cm}^{-1}$ can be attributed to $-\mathrm{C}-\mathrm{H}$ bending arising from 1 and 3 position in benzene ring (isophthalic acid moieties) and $-\mathrm{C}=\mathrm{CH}$ bending arising from isomerization of maleic anhydride to fumarate during polymerization. A broad-spectrum absorption bend at $1105.22 \mathrm{~cm}^{-1}$ confirms the presence of -C-O-C- of ester linkage. A strong absorption peak appearing at $1246.2 \mathrm{~cm}^{-1}$ was assigned to $-\mathrm{C}=\mathrm{C}-$ group of polyester. A medium absorption band at $1447.76 \mathrm{~cm}^{-1}$ can be attributed to $-\mathrm{C}-\mathrm{H}$ bending. The presence of $-\mathrm{C}=\mathrm{O}$ and symmetric $-\mathrm{CH}$ stretching were confirmed by the presence of strong bend at $1736.57 \mathrm{~cm}^{-1}$ and $2979.1 \mathrm{~cm}^{-1}$ respectively. An IR spectrum of cured polyester resin is shown in figure- 9 .

\subsection{Electrical resistance properties of composites}

The key electrical properties of interest for plastics to be used in electrical applications are dielectric strength, dielectric constant, dissipation factor, volume resistivity, surface resistivity and arc resistance. In the present study, volume resistivity, surface resistivity and arc resistance were determined to characterize the composites. 


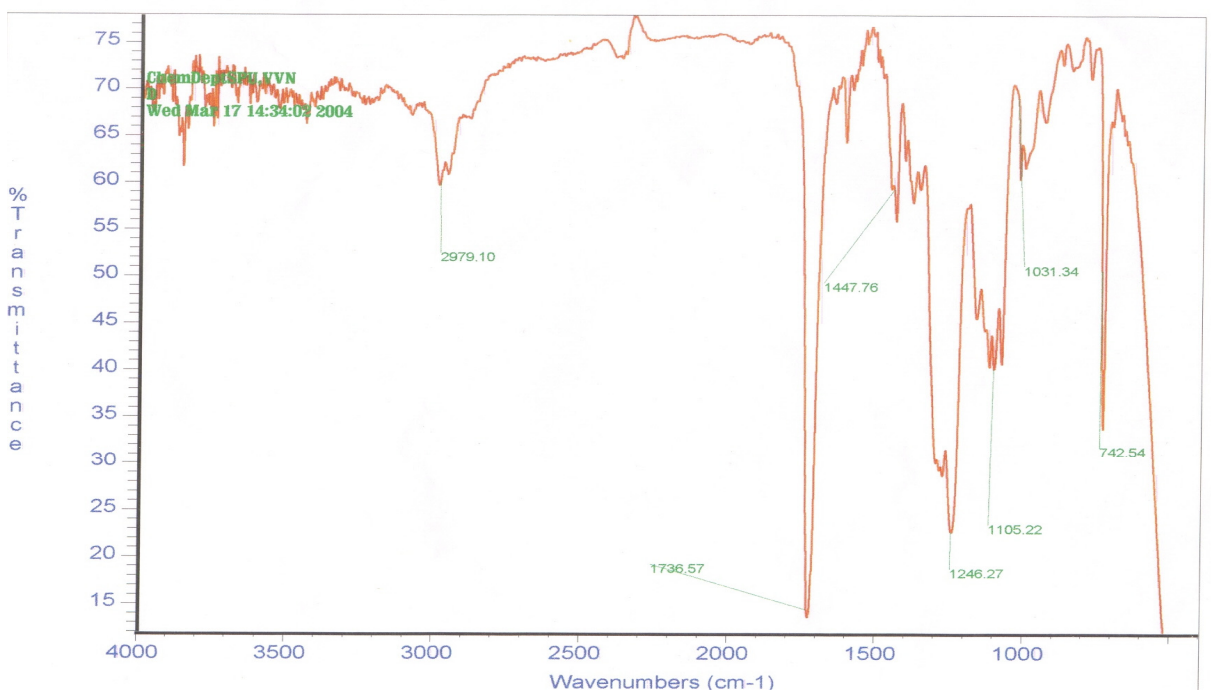

Figure 8. IR Spectra of UPR-2

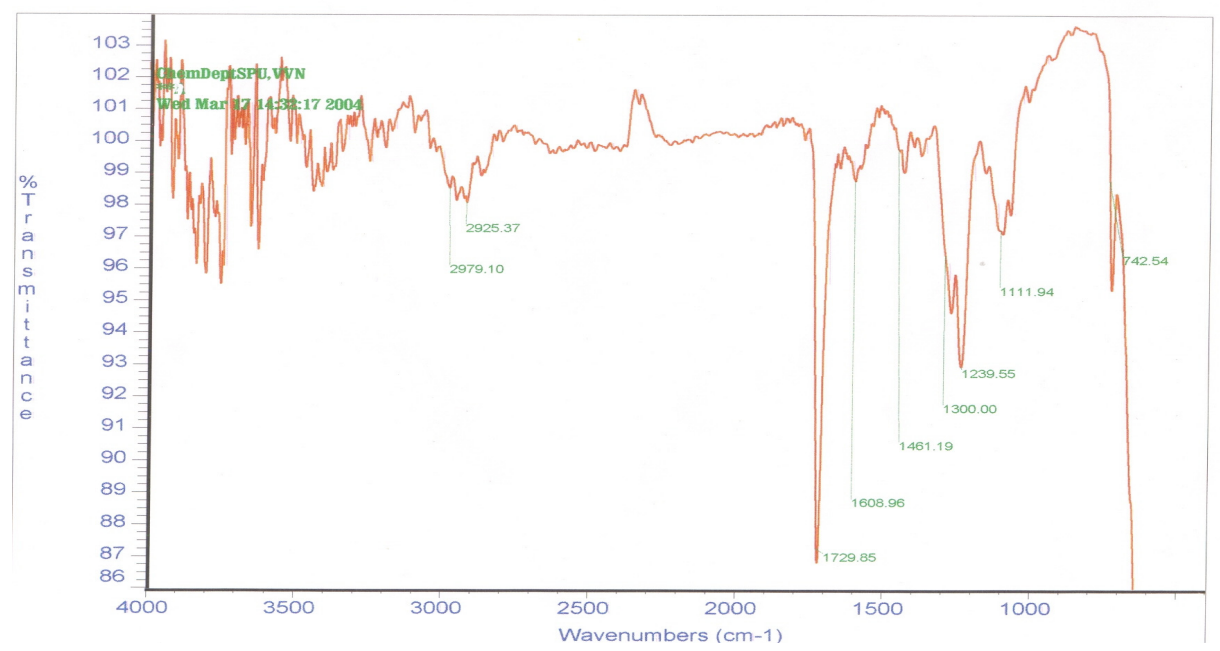

Figure 9. IR Spectra of ERCM-1

\subsubsection{Volume resistivity and surface resistivity}

The volume resistivity and surface resistivity were measured in terms of resistance of composites by a Hewlett Packard Model No. 4329 High resistance meter according to the standard method of testing ASTM D-257 (1978) [167]. A sample sheet was cut from the composite sheet and all dimensions measured as the average of several measurements of length, breadth and thickness. 
For volume resistivity, the specimen was placed between two cylindrical copper electrodes. The electrodes were cleaned before each experiment. The entire rod of the electrode was covered with Teflon and one end of each rod was used for the connection with resistance meter. Volume resistivity was calculated using the following formula.

$$
\text { Volume Resistivity } \rho(\Omega \cdot \mathrm{cm})=\frac{A}{t}(R v)
$$

Where, $\mathrm{A}=$ Area of the specimen, $\mathrm{cm}^{2}, \mathrm{t}=$ Thickness of specimen, $\mathrm{cm}, \mathrm{Rv}=$ Volume resistance $(\Omega)$

For surface resistivity, the electrodes were placed on the same surface of the specimen at a fixed distance and direct voltage was applied between the two electrodes. The resulting current between the electrodes after a given fixed time of application of the voltage was measured ignoring the possible polarization effects. Surface resistivity was calculated using the following formula

$$
\text { Surface resistivity }=\frac{\text { normal voltage gradient }}{\text { current per unit width of current path }}
$$

The tests were carried out with all the prepared composite sheets and the data are reported in the Table-4.

\subsubsection{Arc resistance}

The arc resistance of composites was measured according to standard method of testing ASTM D- 495 (1989) [168], which is high voltage, low current dry arc resistance of solid electrical insulating Material. Figure 10 Illustrates a typical setup for an arc resistance test.

Voltage was applied to test sample and its severity increased in steps until the failure occurred. Arc resistance was measured as the time (sec) at which the surface between two electrodes becomes conductive. The results of arc resistance of all composites under study has been obtained and reported in Table- 4 .

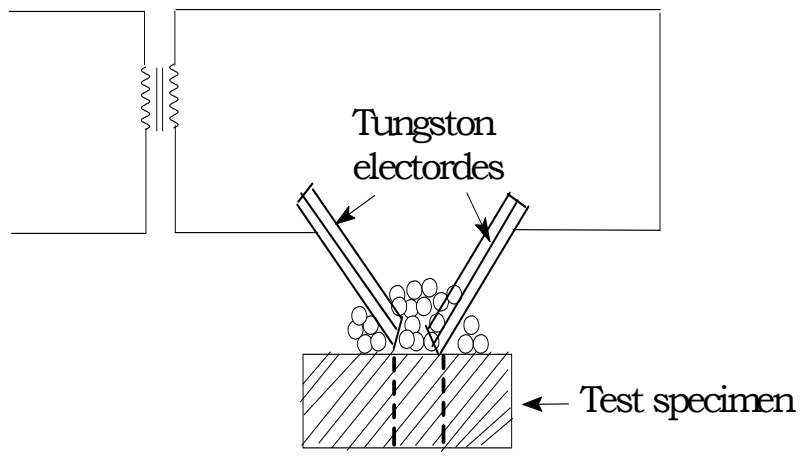

Figure 10. Arc Resistance Test 
Table-4 represents arc resistance, surface resistivity and volume resistivity of filled and unfilled composites. In the present study, the values of surface resistivity and volume resistivity are in the range $1.8 \times 10^{18}-10.9 \times 10^{17}$. The reported values for asbestos filled melamine are $1.2 \times 10^{12}$. Urea-formaldehyde resins show the values in the range of $10^{12}-10^{13}$. Thus the result of present study are in good agreement with the reported value of $\mathrm{PF}, \mathrm{MF}$ and UF resins. The results clearly indicate that the composites of present study can be used in all electrical applications where PF, MF and UF resins are used. Plastics such as epoxies, polyethylenes and fluorocarbons are excellent arc-resistant materials with arc resistance of 120-200 sec and above. It has been reported that arc resistance of plastics can be improved substantially by the addition of fillers such as glass, mineral, wood flour, asbestos and other inorganic fillers. In the present study all the composites show arc resistance in the range of 158-169 sec indicating very good arc resistance.

\begin{tabular}{|l|l|l|l|l|l|l|}
\hline Sample & $\begin{array}{l}\text { Arc } \\
\text { Resistance in } \\
\text { Sec. }\end{array}$ & $\begin{array}{l}\text { Surface } \\
\text { Resistivity in } \\
\Omega \cdot 10^{17}\end{array}$ & $\begin{array}{l}\text { Volume } \\
\text { Resistivity in } \\
\Omega \quad \text { Cm } \cdot 10^{18}\end{array}$ & $\begin{array}{l}\text { Izod Impact } \\
\text { in J/cm }\end{array}$ & $\begin{array}{l}\text { Flexural } \\
\text { Strength in } \\
\mathrm{MPa}\end{array}$ & $\begin{array}{l}\text { Rockwell } \\
\text { Hardness } \\
(\mathrm{M})\end{array}$ \\
\hline ERC-1 & 150 & 2.1 & 1.3 & 5.44 & 239.89 & 60 \\
\hline ERC-2 & 162 & 7.9 & 2.0 & 8.35 & 238.90 & 65 \\
\hline ERC-3 & 164 & 8.7 & 3.3 & 11.00 & 240.00 & 69 \\
\hline ERC-4 & 167 & 9.9 & 3.5 & 12.25 & 241.15 & 72 \\
\hline ERC-5 & 158 & 7.8 & 1.8 & 5.67 & 241.86 & 61 \\
\hline ERC-6 & 161 & 8.5 & 2.6 & 6.95 & 244.98 & 63 \\
\hline ERC-7 & 163 & 8.9 & 3.0 & 7.38 & 246.68 & 64 \\
\hline ERC-8 & $\begin{array}{l}\text { Leaching of } \\
\text { filler }\end{array}$ & $\begin{array}{l}\text { Leaching of } \\
\text { filler }\end{array}$ & $\begin{array}{l}\text { Leaching of } \\
\text { filler }\end{array}$ & $\begin{array}{l}\text { Leaching of } \\
\text { filler }\end{array}$ & $\begin{array}{l}\text { Leaching of } \\
\text { filler }\end{array}$ & $\begin{array}{l}\text { Leaching of } \\
\text { filler }\end{array}$ \\
\hline ERC-9 & 161 & 8.9 & 2.1 & 7.15 & 242.91 & 63 \\
\hline ERC-10 & 165 & 9.9 & 3.6 & 10.10 & 246.84 & 66 \\
\hline ERC-11 & 168 & 10.8 & 4.5 & 11.73 & 248.88 & 68 \\
\hline ERC-12 & 169 & 11.2 & 4.9 & 12.20 & 249.92 & 69 \\
\hline
\end{tabular}

Table 4. Electrical and Mechanical Properties of Composites [169-170]

\subsection{Mechanical properties of electrical resistance composites}

Mechanical properties measured in this study include Izod impact strength, Rockwell Hardness and Flexural strength (table-4). The unbeatable combination of characteristic such as ease of fabrication, low cost, light weight and excellent insulation properties have made composite materials to be one of the most desirable materials for electrical application such as insulators, printed circuit boards, circuit breakers, cabinets etc. Arc resistance, surface resistivity and volume resistivity were evaluated for all the composites filled with different weight percentages of fillers. The arc resistance, surface resistivity and volume resistivity increases with increase in amount of filler because kaolin, surface treated kaolin and mica are electrically inert materials whose increased amount in laminates improves electrical behaviour. Surface treatment of fillers improves the mechanical as well as electrical 
performances because surface treatment of kaolin with the coupling agents will bridged polymer molecules and mineral particles and have the unique ability to substantially improve the bond strength between organic polymer and kaolin particles. Due to these fillers can be easily and uniformly dispersed throughout the polymer matrix and leaching of filler from the polymer matrix is prevented. This will ultimately improve the performance of composites. Composites prepared using fillers give better electrical performance than unfilled composites and also there is increase in electrical resistance with increase in amount of filler, but when amount of filler exceeds 30 weight percent, untreated fillers i. e. raw kaolin and mica leaches out from the polymer matrix. While surface treated kaolin doesn't leach out of the polymer matrix. The effects of concentration of filler and surface treatment of filler on mechanical properties have been examined. The results revealed that concentration of filler and surface treatment of filler remarkably influence the mechanical and electrical behaviour of composites [103-104]. Also cost-effective electrical composites can be formulated with competitive performance by using cheaper and widely available fillers. The composites can be used for electrical, electronic and electro technical applications like circuit breakers, switch board cabinets, automotive distributor caps, printed circuit board etc.

\section{Acrylic modified low styrene emission unsaturated polyester resin having improved fire resistance and mechanical properties}

\subsection{Introduction}

Unsaturated polyester resins are one of the most important matrix resins for commodity glass fibre reinforced composites [171]. They are obtained in a two step process; first unsaturated and saturated acids or anhydrides are reacted with diols in a polycondensation reaction, secondly the resulting linear polyester prepolymer is dissolved in styrene into syrup-like resin [172-173]. The styrene acts both as a cross-linking agent and as a viscosity reducer so that the resin can be processed. In conventional unsaturated polyesters the styrene content varies between 35- 45wt \%. The styrene monomer in the unsaturated polyester resin is an environmental and occupational health problem due to evaporation and emissions, which occur during the processing of the resin. In 1992 it was found that about $75 \%$ of the workers in the reinforced plastic industry in Finland are exposed to styrene concentrations exceeding the current occupational exposure limit of 20ppm [174]. Much improvement of the work environment has been made by using proper ventilation systems together with styrene absorbing collection systems, by improvement of the work practice and the housekeeping, by using personal respiratory protection and by using low styrene emission resins in the industry. During the end of the 1980.s the environmental problems caused by styrene emission from the processing of unsaturated polyesters were debated a lot in the society, especially in the Nordic countries. The producers of unsaturated polyesters started therefore to search actively for alternatives to styrene and started to develop additives inhibiting styrene emission.

This work deals with the development of low styrene emission unsaturated polyester resins with improved fire resistance and mechanical properties. These studies showed clearly that 
the styrene emission cannot be avoided as long as the basic chemical composition is kept unchanged. Structural modifications are therefore needed. The fire behaviour of composites can also be improved by using a halogenated resin [175] in place of a traditional resin. The main disadvantage of this solution is that a fire could create toxic and possibly corrosive smoke [176]. Recently, environmental problems relating to brominated flame retardants (BFRs) have become a matter of greater concern than ever before, because of the recent marked increase in levels of polybrominated diphenyl ethers (PBDEs) found in human milk in Sweden and North America [177]. It is shown in this work that non-halogen flame retardants are very effective and does not create any toxic and corrosive smoke in unsaturated polyester resins. Their advantages lie in their high effectiveness, which enables very low concentrations to be used, while at the same time meeting the most stringent requirements.

The experimental work in this article deals synthetic modifications of unsaturated polyester resin in order to achieve better fire resistance and mechanical properties, lower styrene emission, better styrene solubility and lower processing viscosity. These new ecological unsaturated polyester resins will be used for marine, automotive, electric and electronic, building construction, sport and leisure, domestic and sanitary appliances, furniture as well as military applications. Two concepts were used for development of these new ecological unsaturated polyester resins; Introduction of acrylic monomers viz; Methyl methacrylate (MMA), Butyl methacrylate (BMA) and Acrylonitrile (AN) into the unsaturated polyester resins to reduce styrene emission and use of halogen free fire resistance fillers (Zinc borate and antimony trioxide) in place of halogenated fillers. The main disadvantage of halogenated fillers is that a fire could create toxic and possibly corrosive smoke. Liquid crystalline unsaturated polyester resins were possible to synthesize and it was also possible to prepare solutions of unsaturated polyesters in styrene. By modification with acrylic monomers it is possible to prepare resins with a styrene content as low as $20 \mathrm{wt} \%$. The mechanical and fire resistance properties of the cured samples depending on the type of acrylic monomer and amount and type of filler. Modification of unsaturated polyesters in this way is a possibility to get unsaturated polyester resins with low styrene emission, better fire resistance and mechanical properties, lower shrinkage, reduced brittleness and increased flexibility.

\subsection{Synthesis of acrylic modified low styrene emission unsaturated polyester resin}

Unsaturated polyester resin was prepared in the present work by the technique reported by B.Parkyn [171]. A mixture of $1.25 \mathrm{~mol}$ Propylene glycol (PG), 0.5mol Phthalic anhydride, $0.2 \%$ p-Toluene sulfonic acid (PTSA) and Xylene as distillating solvent was charged in a three-neck reaction kettle equipped with stirrer, thermometer, nitrogen-gas introducing tube, Dean \& Stark apparatus, and water condenser. The mixture was mechanically stirred and heated at $120^{\circ} \mathrm{C}$ under nitrogen gas stream, and esterification was carried out while removing water formed by the reaction from the reaction system. When reaction mass becomes clear, it was allowed to cool. When the temperature was dropped to $80^{\circ} \mathrm{C}, 0.5 \mathrm{~mol}$ 
Maleic anhydride (MA) was added and continues heating at $150-200^{\circ} \mathrm{C}$ until an acid number of 20 were reached. The Xylene was completely distilled out and reaction product was allowed to cool. When the temperature was dropped to $160^{\circ} \mathrm{C}, 20 \mathrm{mg}$ of hydroquinone was added. When the temperature was dropped to below $100^{\circ} \mathrm{C}$, an amount of styrene was added to a styrene content of $20 \%$.

Unsaturated polyester resin was modified by replacing $15 \%$ styrene (table-5) by different acrylic monomers viz. Methyl methacrylate (MMA), Butyl methacrylate (BMA) and Acrylonitrile (AN). Modification of unsaturated polyester resin was carried out in three neck flask equipped with stirrer. Firstly required quantity of styrene diluted unsaturated polyester resin (20\% styrene) was added and then $15 \%$ of acrylic monomers were added with constant stirring at room temperature. The resultant modified unsaturated polyester resin was named as low styrene emission unsaturated polyester resin (LSEUPR).

\begin{tabular}{|c|c|c|c|c|}
\hline \multirow{2}{*}{$\begin{array}{c}\text { Low Styrene Emission } \\
\text { Unsaturated Polyester Resin }\end{array}$} & \multirow{2}{*}{$\begin{array}{c}\text { Styrene } \\
\text { in Wt } \%\end{array}$} & \multicolumn{3}{|c|}{ Acrylic Monomer in Wt \% } \\
\cline { 3 - 5 } & 20 & MMA & BMA & AN \\
\hline LSEUPR-1 & 20 & 15 & - & - \\
\hline LSEUPR-2 & 20 & 15 & - & - \\
\hline LSEUPR-3 & 20 & 15 & - & - \\
\hline LSEUPR-4 & 20 & 15 & - & - \\
\hline LSEUPR-5 & 20 & - & 15 & - \\
\hline LSEUPR-6 & 20 & - & 15 & - \\
\hline LSEUPR-7 & 20 & - & 15 & - \\
\hline LSEUPR-8 & 20 & - & 15 & - \\
\hline LSEUPR-9 & 20 & - & 15 & - \\
\hline LSEUPR-10 & 20 & - & - & 15 \\
\hline LSEUPR-11 & 20 & - & - & 15 \\
\hline LSEUPR-12 & 20 & - & - & 15 \\
\hline LSEUPR-13 & 20 & - & - & 15 \\
\hline LSEUPR-14 & 20 & - & - & 15 \\
\hline LSEUPR-15 & & - & & \\
\hline
\end{tabular}

Table 5. Low Styrene Emission Unsaturated Polyester Resin [178]

\subsection{Fire resistance formulation and composite preparation}

In present study low styrene emission unsaturated polyester resins were used with antimony trioxide and zinc borate for composite preparation (table-6). Several combinations were tested to determine effects of additives in the polymer formulations. Fire resistance formulations were prepared by adding these additives in different amounts (10 to $30 \mathrm{wt} \%$ ) in low styrene emission unsaturated polyester resin. Additives in different amount were mixed with low styrene emission unsaturated polyester resin in a round bottom flask 
equipped with high speed agitator by means of agitation. The resultant formulations were compounded with glass fibre as reinforcing materials and benzoyl peroxide as curing catalyst for composite preparation.

Composites were prepared by hand lay-up technique using about 50 weight percent of glass fibre and filler. After application of resin on glass fibre, the composites were cured by compression moulding technique at $100 \mathrm{psi}$ pressure and $120^{\circ} \mathrm{C}$ temperature for 30 minutes. $1 \%$ Benzoyl peroxide (BPO) was used as an initiator. The composites obtained from fire resistance formulations were characterized by Limiting oxygen index according to ASTM D2863[91].

\begin{tabular}{|c|c|c|c|c|c|c|c|c|c|}
\hline $\begin{array}{c}\text { Composite } \\
\text { Code }\end{array}$ & $\begin{array}{c}\text { Low Styrene } \\
\text { Emission } \\
\text { Unsaturated } \\
\text { Polyester Resin } \\
\text { Composition 100 } \\
\text { Wt } \%\end{array}$ & $\begin{array}{c}\text { Reinfo- } \\
\text { rcement }\end{array}$ & $\begin{array}{c}\text { Fillers in Wt } \\
\%\end{array}$ & $\begin{array}{c}\text { Catalyst } \\
\text { in Wt \% }\end{array}$ & $\begin{array}{c}\text { Limiting } \\
\text { Oxygen } \\
\text { Index } \\
\text { (LOI) in } \\
\%\end{array}$ & $\begin{array}{c}\text { Zinc } \\
\text { borate }\end{array}$ & $\begin{array}{c}\text { Impod } \\
\text { in J/cm }\end{array}$ & $\begin{array}{c}\text { Flexural } \\
\text { Strength } \\
\text { in MPa }\end{array}$ & $\begin{array}{c}\text { Rockwell } \\
\text { Hardness } \\
(\mathrm{M})\end{array}$ \\
\hline LSEUPRC-1 & LSEUPR-1 (100) & 100 & - & - & 2 & 21 & 5.09 & 238.85 & 59 \\
\hline LSEUPRC-2 & LSEUPR-2 (100) & 70 & 30 & - & 2 & 25 & 4.15 & 230.85 & 57 \\
\hline LSEUPRC-3 & LSEUPR-3 (100) & 70 & 20 & 10 & 2 & 28 & 7.25 & 242.00 & 61 \\
\hline LSEUPRC-4 & LSEUPR-4 (100) & 70 & 10 & 20 & 2 & 30 & 10.10 & 246.15 & 63 \\
\hline LSEUPRC-5 & LSEUPR-5 (100) & 70 & - & 30 & 2 & 32 & 11.80 & 247.90 & 66 \\
\hline LSEUPRC-6 & LSEUPR-6 (100) & 100 & - & - & 2 & 22 & 4.90 & 240.00 & 58 \\
\hline LSEUPRC-7 & LSEUPR-7 (100) & 70 & 30 & - & 2 & 26 & 4.00 & 231.85 & 56 \\
\hline LSEUPRC-8 & LSEUPR-8 (100) & 70 & 20 & 10 & 2 & 29 & 7.15 & 242.25 & 60 \\
\hline LSEUPRC-9 & LSEUPR-9 (100) & 70 & 10 & 20 & 2 & 31 & 10.00 & 246.55 & 62 \\
\hline LSEUPRC-10 & LSEUPR-10 (100) & 70 & - & 30 & 2 & 34 & 11.55 & 248.10 & 65 \\
\hline LSEUPRC-11 & LSEUPR-11 (100) & 100 & - & - & 2 & 21 & 5.65 & 235.90 & 60 \\
\hline LSEUPRC-12 & LSEUPR-12 (100) & 70 & 30 & - & 2 & 25 & 4.85 & 228.15 & 58 \\
\hline LSEUPRC-13 & LSEUPR-13 (100) & 70 & 20 & 10 & 2 & 27 & 7.65 & 240.00 & 63 \\
\hline LSEUPRC-14 & LSEUPR-14 (100) & 70 & 10 & 20 & 2 & 29 & 10.20 & 244.35 & 66 \\
\hline LSEUPRC-15 & LSEUPR-15 (100) & 70 & - & 30 & 2 & 31 & 11.85 & 246.15 & 68 \\
\hline
\end{tabular}

LSEUPRC: Low Styrene Emission Unsaturated Polyester Resin Composites

Table 6. Fire Resistance Formulation and Properties with Mechanical Properties [178]

\subsection{Fire resistance properties of composites}

In this work, fire behaviour of composites was evaluated. Many procedures exist to evaluate fire behaviour of the composite materials [96-97].The key fire resistance properties of interest for polymers to be used in fire resistance applications are ease of ignition, flame spread, ease of extinction, smoke obscuration, smoke toxicity, heat release rate and limiting oxygen index. In the present study limiting oxygen index (ASTM D-2863) was determined to characterize the composites. Table- 6 represents limiting oxygen index of filled and 
unfilled composites. In the present study values of limiting oxygen index of filled composites are in the range of 25-34. Material is normally considered as flame resistance if LOI is greater than 26[99]. Thus the results of present study are in good agreement with the reported values. The results clearly indicate that the composites of present study can be used in all fire resistance applications. Composites prepared using fillers give better fire resistance than unfilled composites and also there is increase in fire resistance with increase in amount of filler.

\subsection{Mechanical properties of composites}

Mechanical properties measured in this study include Izod impact, Rockwell Hardness and Flexural strength. Table-6 represents Izod impact strength, Rockwell hardness and flexural strength. Mechanical properties of laminates improve remarkably with introduction of acrylic monomers and fillers. Increase in strength with increase in filler content is due to the reinforcement action provided by the filler particles to the polymer matrix. Laminates prepared using LSEUPR and fillers give better mechanical performance than traditional unfilled laminates and also there is increase in mechanical properties with increase in amount of filler. Also acrylic modification by using various acrylic monomers viz; methyl methacrylate, butyl methacrylate and acrylonitrile of unsaturated polyester resins greatly influences mechanical properties and also reduced styrene emission. Butyl methacrylate modified LSEUPRC gives better flexural strength than methyl methacrylate and Acrylonitrile modified LSEUPRC. Methyl methacrylate modified LSEUPRC gives better flexural strength than acrylonitrile modified LSEUPRC but lower than butyl methacrylate modified unsaturated polyester resin. Acrylonitrile modified LSEUPRC shows better Izod impact strength and Rockwell hardness than methyl methacrylate and butyl methacrylate modified LSEUPRC.

Mechanical properties of composites improve remarkably with increase in the filler content except in antimony trioxide. Increase in mechanical properties with increase in filler content is due to the reinforcement action provided by the filler particles to the polymer matrix [103104]. Composites prepared using fillers antimony trioxide and zinc borate gives better performance than unfilled composites and also there is increase in mechanical properties with increase in amount of fillers. Antimony trioxide gives poor results compared to zinc borate and also mechanical performance decreases with increase in amount as antimony trioxide is poor in mechanical performance. The results revealed that concentration and type of filler remarkably influence the mechanical and fire behaviour of composites. The study reveals that acrylic modification of unsaturated polyester resin by partially replacing styrene monomer drastically reduces styrene emission and greatly influences mechanical properties.

\section{Conclusion}

Composites prepared using fillers antimony trioxide, fly ash, zinc borate, hydroxyapatite, mica, surface treated kaolin and raw kaolin gives better performance than unfilled composites and also there is increase in mechanical properties with increase in amount of fillers, but leaching of fillers observed in mica and raw kaolin when amount exceeds more 
than 30 weight \%, while the surface treated kaolin filled composites doesn't show such problem. Antimony trioxide and fly ash gives poor results compared to other fillers and also mechanical performance decreases with increase in amount as antimony trioxide has poor binding property. Also composites prepared using surface treated kaolin gives better performance than composites prepared from antimony trioxide, fly ash, zinc borate, hydroxyapatite, mica and raw kaolin due to surface treatment.

The results also revealed that the fire retardancy of the polyester based composites can be improved by using non traditional fillers like zinc borate, hydroxyapatite and fly ash. They have an advantage over a traditional filler antimony oxide to increase the fire retardancy without decreasing mechanical and thermal properties of the composites. There is however, considerable variation in the efficiency of these fillers. The adequacy of the fire resistance performance of these filled composites is dependent on both types of filler and incorporation level of the fillers. Hydroxyapatite and zinc borate gives good results as compared to other fillers. Tests show that the fire results are good with a decrease in heat and smoke production during combustion and also decomposition does not release additional toxic gases.

Composites prepared using fillers give better electrical performance than unfilled composites and also there is increase in electrical resistance with increase in amount of filler. Surface treatment of fillers improves the mechanical as well as electrical performances because surface treatment of kaolin with the coupling agents will bridged polymer molecules and mineral particles and have the unique ability to substantially improve the bond strength between organic polymer and kaolin particles. Due to this filler can be easily and uniformly dispersed throughout the polymer matrix and leaching of filler from the polymer matrix is prevented. This will ultimately improve the performance of composites.

The study reveals that acrylic modification of unsaturated polyester resin by partially replacing styrene monomer drastically reduces styrene emission and greatly influences mechanical properties. From overall study we conclude that composites prepared from unsaturated polyester resin using additives like hydroxyapatite, zinc borate, fly ash, antimony trioxide, mica, surface treated kaolin and raw kaolin are of better/upgraded in fire resistance and electrical resistance with good mechanical properties and acrylic modification by partially replacing styrene monomer reduces styrene emission.

\section{Author details}

Bharat Dholakiya

Applied Chemistry Department, Sardar Vallabhbhai National Institute of Technology (SVNIT), Gujarat, India

\section{References}

[1] Bjorksten Research Laboratories; Polyesters and Their Applications; Reinhold; New York; 1956. 
[2] V. V. Karshak and S. V. Vinogradova; Polyesters; Pergamon; New York; 1965.

[3] I. Goodman; Encyclopedia of Polymer Science and Engineering; 2nd ed.; 12; Wiley; New York; 1988.

[4] I. Goodman; J. A. Rhys; Polyesters; Saturated Polymers; Iliffe Books; London; 1; 1965.

[5] I. Goodman; 2nd ed.; 16: 159; Wiley: New York, 1968.

[6] P. W. Morgan; Condensation Polymers; By Interfacial and Solution Methods; Inerscience Publishers; New York; 1965.

[7] W. H. Carothers; J. Am. Chem. Soc.; 51; 2548; 1929.

[8] J. R. Whinfield; Nature; 158; 930; 1946.

[9] M. P. Stevens; Polymer Chemistry; 2nd ed.; Oxford University Press. Inc.; pp 338-358; 1999.

[10] H. Makoto; M. Nobuo and M. Masatoshi; Jpn. Pat. JP 2001 262, 031; 2000; CA. 135 $243881 y ; 2001$.

[11] L. Geng; J. A. Baghdachi and J. L. Massingill; Jr. $\quad$ Polym. Material Sci. Eng. 85; 135$136 ; 2001$.

[12] C. Eddy; Verfkroniek; 74(4); 13-15; CA. 135 290199s; 2001.

[13] T. Hiroyuki; O. Sumio and F. Tadashi; Jpn Pat. JP 2001 279, 150; CA. 135 290293t; 2001; 2002.

[14] H. Norimitsu; T. Shinichi; T. Toshiyuki and S. Isao; Shikizai Kyokaishi; 74(2); 57-62; CA. 135 290170a; 2001.

[15] K. M. England; J. W. Gillespie; W. John, Jr. and B. K. Fink; J. Compos. Mater.; 35(15); 1392-1414; 2001.

[16] M. Koichi and I. Hidemi; Jpn. Pat. JP 2001 293, 732; C.A. 135 304974e; 2002.

[17] G. Jianjun and J. Wugang; Gongcheng suliao Ying Young; 28(3); CA. 135 332164j; 2000.

[18] M. Fumio; M. Katsuhisa; H. Yoshitaka; M. Takashi; S. Junnosuke; S. Fumiaki; H. Nobuhito and N. Takeshi; Jpn. Pat. JP 2001 287; 313; CA..135 304831f; 2002.

[19] H. Yasumochi and K. Kazuo; Jpn; Pat. JP. 2001 294; 688; CA.135 319323r; 2000.

[20] H. Takashi; Jpn. Pat JP. 77 00; 509; CA. 87 109445w; 1975.

[21] R. E. Young; “Unsaturated Polyester Technology"; P.E. Bruins; Ed. Garden and Breach; New York; 315; 1976.

[22] S. H. Ridrr and E. E. Hardy; "Polymerization and Polycondensation Processes"; N.A.J.Platzers Ed; Advances in Chemistry Series no. 34; American Chemical Society; Washington Dc.; 173; 1962.

[23] H. V. Boenig; "Unsaturated Polyesters"; Structure and Properties; Elsevier; Amsterdam; 1964.

[24] B. Parkyn; F. Lamb and B. V. Clinton; Polyesters; Unsaturated Polyesters and Polyester Plasticizers; Elsevier; New York; 2; 1967.

[25] A. Frodet; and P. Arland; "Unsaturated Polyesters"; Comprehensive Polymer Science; Pargamon Press, New York, Ch. 19, 331; 1989.

[26] H. F. Mark; N. G. Gayord and N. M. Bikales; Encyclopedia of Polymer Science and Technology; John Wiley and Sons; New York; 1970.

[27] H. V. Boenig; Unsaturated Polyesters"; Elsevier Publishing Co.; Amsterdam; 1964.

[28] J. A. Arvin and W. H. Carothers; J.Am. Chem. Soc.; 51; 2560; C.A. 23, 4438; 1929. 
[29] Ford Motor Co. Ltd.; Brit.; 991, 561; C.A. 63, 7208d; 1965.

[30] G. Corrado; E. Bertotti and B. Sopino; Ger. Often.; 2; 952, 679; C.A. 93, 16916p; 1980.

[31] M. Ochsenbein and J. P. Olliver; Ger. Often.; 3; 033; 063; C.A. 94; 193123q; 1981.

[32] K. H. Schmidt; A. Weber; D. Rowe and B. Brinker; US; 3,418,286; C.A. 70, 38474r; 1968.

[33] T. Sarai; H. Miyashita and Y. Sano; Japan, 69 31,832; C.A. 72, 112258; 1970.

[34] M. Hitoshi; S. Hatsuhiko and A. Mamoru.; JP 2003183489; Jpn. Kokai Tokkyo Koho; 2003.

[35] Y. Howard B.; V. James F. and M. Karen E.; EP 1132429; Eur. Pat. Appl.; 2001.

[36] O. Toshishide; JP 2002294057; Jpn. Kokai Tokkyo Koho; 2002.

[37] N. T. Qazvini and N. Mohammadi; Polymer; 46(21); 9088-9096; 2005.

[38] Q. Jun-min and J. Zhi-hao; School of Materials Science and Engineering; Xi'an Jiaotong University; Xi'an, Peop. Rep. China. Reguxing Shuzhi; 17(4); 31-35; 2002.

[39] Li, Tong.; Tianjin Synthetic Material Res. Inst., Tianjin; Peop. Rep. China.; Reguxing Shuzhi; 17(3); 31-35; 2002.

[40] P. Penezek; Polymery; 17(5); 248; C.A. 77; 127278s; 1972.

[41] W. Freitag; W. Sarfert and W. Lohs; Ger (East). DD; 260; 834; C.A. 111, 24521g; 1989.

[42] J. Korbar; J. Golob and A. Sebenik; Polym. Eng. Sci.; 33(18); 1212; C.A. 119, 250590a; 1993.

[43] Owens Corning Fibre Glass Corp.; Belg.; 867; 256; C.A. 90, 104895v; 1979.

[44] S. Miyamato; S. Shimazu; F. Sato; Y. Higuchi; T. Abe and K. Yamato; Ger. Often; 3; 019; 859; C.A. 94, 192925r; 1981.

[45] K. H. Jin; P. G. Guk and S. C. Dong.; KR 2000061809; Repub. Korean Kongkae TaehoKongbo; 2000.

[46] B. Michael A.; and C. Richard.; US 6472069, U.S.; 2002.

[47] E. K. Gamstedt; M. Skrifvars; T. K. Jacobsen; Composites; Part A: Applied Science and Manufacturing; 33A (9); 1239-1252; 2002.

[48] M. P. Stevens; Polymer Chemistry; 2nd ed.; Oxford University Press. Inc.; 106-120; 1999.

[49] M R.C. Nametz; J.D. Pietro and I.N. Einhorn; Amer. Chem. Soc.; 28(1); 204-24; 1968.

[50] Tanaka and E. Iwami; Jpn Pat. JP 62 201; 326; CA. 108 22799t; 1986.

[51] N.Yoshihiro and I. Yasuaki; Jpn Pat. JP 11 60, 858; CA. 130 223995g; 1997.

[52] N. Kazunri and K. Haruyuki; Jpn Pat JP 11 116, 779; CA. 130 353416e; 1997.

[53] O. Toshishide; JP 2002294057; 7pp; Jpn. Kokai Tokkyo Koho; 2002.

[54] W. Shoichi; N. Seiichi; K. Koichi and U. Tomoyuki; JP 11140287; 8pp; Jpn. Kokai Tokkyo Koho; 1999

[55] B. Jaljakumari; K. G. K. Warrier; K. G. Satyanarayana and C. Pavithran; Journal of Reinforced Plastics and Composites; 7(5); 402-412; 1998.

[56] D. Baral; P. P. De and G. B. Nando; Polymer Degradation and Stability; 65; 47-51; 1999.

[57] A. L. G. Saad and A. F. Younan; Polymer Degradation and Stability; 50; 133-140; 1995.

[58] D. K. Brown and D. W. Chalmers; The management of safety of warships in the UK; Transaction of the Royal Institution of Naval Architects; 132; 1990.

[59] 59C. M. Sprague; P. E. Robert and M. A. Blanchard; A methodology for evaluation of ship fire safety; Naval Engineers; 104; 1992. 
[60] Fire safety on ships; Development into the 21st century; The Institute of Marine Engineers; London; 106; 1994.

[61] K. H. G. Ashbee and R. C. Wyatt; Proc. Royal Soc.; London; A312; 553; 1969.

[62] B. Mortaigne; V. Bellenger and J. Verdu; Polymer Networks and Blends; 2(4); 187; 1992.

[63] R. D. Deanin; Flame Retardants for Polyolefins; Polymeric Materials Science and Engineering; 66; 320-322; 1989.

[64] K. Yashuiro; I. Hiroyuki and T. Mitsuo; Jpn Kokai Tokkyo Koho; JP 2002188015; 11pp; 2002.

[65] L. In-Tae; S. Jae-Kyong and K. Kyo-Myong; Repub. Korea; KR 9509156; 1995.

[66] W. Shoichi; N. Seiichi; K. Koicji and U. Tomoyuki; Jpn Kokai Tokkyo Koho; JP 11140287; 8pp; 1999.

[67] O. Yasuo; Jpn Kokai Tokkyo Koho; JP 10095910; 10pp; 1998.

[68] T. Susumu; T. Yuichi and I. Yuji; Jpn Kokai Tokkyo Koho; JP 10087977; 8pp; 1998.

[69] K. Hideyuki; O. Toshe; M. Masaaki and F. Kenju; Jpn Kokai Tokkyo Koho; JP 07173362; 11pp; 1995.

[70] Y. Yasushi; M. Haruhiko; N. Asaichi and K. Tsukasa; Jpn Kokai Tokkyo Koho; JP 02283442; 4pp; 1990.

[71] V. Eduard; CS 216617; 5pp; 1984.

[72] K. Erich; US 4139577; 7pp; 1979.

[73] O. Takao and M. Masahiko; Jpn Kokai Tokkyo Koho; JP 46006865; 7pp; 1971.

[74] A. R. Jack and J. A. Clive; GB 1222738; 5pp; 1971.

[75] M. Shunli; H. Silie; L. Shuhong; X. Zhijun and X. Bingshi; Faming Zhuanli Shenqing Gongkai Shoumingshu; CN 1379078; 6pp; 2002.

[76] W. Shui-Ping; G. Wen-Hua and Z. Jia; Journal of Wuhan University of Technology; Material Science Edition; 17(4); 86-88; 2002.

[77] A. D. La Rosa; O. Motta and A. Recca; Journal of Polymer Engineering; 22(5); 341-352; 2002.

[78] Q. Jun-Min and J. Zhi-hao; Reguxing Shuzhi; 17(4); 31-35; 2002.

[79] L. Tong; Reguxing Shuzhi; 17(3); 31-35; 2002.

[80] B. K. Kandola; O. R. Horrocks; P. Myler and D. Blair; Composites Part-A; Applied Science And Manufacturing; 33A(6); 805-817; 2002.

[81] S. Yeng-Fong and J. Ru-Jong; Polymer Degradation and Stability; 77(1); 67-76; 2002.

[82] Z. Liming and G. Wenfeng; Wuhan Gongye Daxue Xuebao; 23(2); 15-17; 2001.

[83] B. Gaoliang; Faming Zhuanli Shenqing Gongkai Shuomingshu; CN 1268753; 7pp; 2000.

[84] S. Yasutoshi; Jpn Kokai Tokkyo Koho; JP 46040423; 5pp; 1971.

[85] L. B. Manfredi; E. S. Rodríguez; M. W. Przybylak and A. Vázquez; Polymer Degradation and Stability; 91(2); 255-261; 2006.

[86] B. K. Kandola; M. H. Akonda and A. R. Horrocks; Polymer Degradation and Stability; 88(1); 123-129; 2005.

[87] F. Le Lay and J. Gutierrez; Polymer Degradation and Stability; 44(3); 323-333; 1994.

[88] S. Horold; Polymer Degradation and Stability; 64(3); 419-425; 1999. 
[89] Sunemi, H. T., Fushiki, Y., Nishimura, A., Kawai, Y.: Prepolymer polyester resin compositions and electrical laminates made therefrom, Kanegafuchi Chemical Ind., CA 1337915, 1996

[90] Kim, J., Jeong, D., Son, C., Lee, Y., Kim, E., Moom, I.: Synthesis \& Application of Unsaturated Polyester Resins based on PET Waste, Korean J. Chem. Eng., 24(6), (2007), 1076-1083.

[91] ASTM D - 2963: MODERN Plastics Encyclopedia, McGraw-Hill, New York, 1967, 238.

[92] Bharatkumar Z. Dholakiya: Use of non-traditional fillers to reduce flammability of polyester resin composites; polimeri; 30 (1), (2009), 10-17.

[93] Edith, A.: Thermal Characterization of Polymeric Materials, Turi Acadamic press, 1981.

[94] Wendlandt, W. W., Collins, L. W.: Thermal Analysis, series two, Benchmark papers in Analytical Chemistry, Dowden, Hutchinson and Ross, Inc.,Pennsylvania, 1976.

[95] Turi, E. A,, khanna, Y. P., Taylor, T. J.: A guide to materials, characterization and chemical analysis, Ed.by J.P.sibilia,VHC publishers, 1988, 205.

[96] Tewarson, A.: Flammability Parameters of Materials: Ignition, Combustion, and Fire Propagation, J Fire Sci., 12(1994)4, 329-356.

[97] Tewarson, A., Pion, R. F.: Flammability of plastics-I. Burning intensity, Combustion and Flame, 26(1976), 85-103.

[98] Fennimore, C. P., Martin, F. J.: Flammability and sensitivity of materials in oxygenenriched atmospheres, Mod. Plast., 44(1966)3, 141-148.

[99] Van Krevelen, D. W.: Properties of Polymers, Elservier/North-Holland, New York, 1975.

[100] ASTM D -256: Impact Resistance of Plastics and Electrical Insulating Materials, 1984.

[101] ASTM D-785: Rockwell Hardness of Plastics and Electrical Insulating Materials, 1965.

[102] ASTM D-790: Flexural Properties of Plastics and Electrical Insulating Materials, 1984.

[103] T.K. Jayasree et. al., Effect of Fillers on Mechanical Properties of Dynamically Cross linked Styrene Butadiene Rubber/High Density Polyethylene Blends, Journal of Elastomers and Plastics, 40 (2), 127-146, 2008.

[104] Azhar Iqbal et. el., , The effect of filler concentration on the electrical, thermal, and mechanical properties of carbon particle and carbon fiber-reinforced poly(styrene-coacrylonitrile) composites, Polymer Composites, 28(2), 186-197, 2007.

[105] S. J. Harris; B. Noble and M. J. Owen; Metallographic investigation of the damage caused to GRP by the combined action of electrical, mechanical, and chemical environments; J Mater Sci.; 19; 1596-1604; 1984.

[106] A. Akhtar; J. S. Nadeau; J. Y. Wang; D. P. Romily and C. Taggart; Brittle fracture of non-ceramic insulators; Report for the Canadian Electrical Association (186 T 350); Prepared by the British Columbia Hydro and Power Authority; September 1986.

[107] M. J. Owen; S. J. Harris and B. Noble; Failure of high voltage electrical insulators with pultruded glass fibre-reinforced plastic cores; Composites; 17; 217-226; 1986.

[108] A. Akhtar and J. Y. Wong; Failure analysis of brittle fracture in nonceramic insulators; J Compos Technol Res.; 9; 95-100; 1987.

[109] M. Kumosa; Micro-fracture mechanisms in glass polymer insulator materials under combined effects of electrical, mechanical and environmental stresses; Final Report to the Bonneville Power Administration; Electric Power Research Institute and the 
Western Area Power Administration; Oregon Graduate Institute, Portland; Oregon; July 1994.

[110] M. Kumosa; Q. Qiu; E. Bennett; C. Ek; T. S. McQuarrie and J. M. Braun; Brittle fracture of non-ceramic insulators; Proceedings of the Fracture Mechanics for Hydroelectric Power Systems Symposium '94; Canadian Committee for Research on the Strength and Fracture of Materials (CSFM); BC Hydro; 235-54; 1994.

[111] Q. Qiu; Brittle fracture mechanisms of glass fibre reinforced polymer insulators; Ph.D. Thesis; Oregon Graduate Institute of Science and Technology; Portland; Oregon; October 1995.

[112] M. Kumosa and Q. Qiu; Failure analysis of composite insulators (failure investigation of $500 \mathrm{kV}$ non-ceramic insulators for pacific gas and electric company); Final Report to the Pacific Gas and Electric Company; Department of Engineering; University of Denver; May 1996.

[113] M. Kumosa; H. Shankara Narayan; Q. Qiu and A. Bansal; Brittle fracture of nonceramic suspension insulators with epoxy cone end-fittings; Compos Sci Technol.; 57; 739-751; 1997.

[114] Interview with Maciej Kumosa; Research of brittle fractures in composite insulators; Insulator News and Market Report; 46-51; July/August 1997.

[115] J.T. Burnham and R J.Waidelich; Gunshot damage to ceramic and nonceramic insulators; IEEE Trans Power Deliv.;12(4);1651-1656; 1997.

[116] M. Kumosa et al.; Micro-fracture mechanisms in glass/polymer insulator materials under the combined effect of mechanical, electrical and environmental stresses; Final report to BPA,APA,PG and E,WAPA and NRECA, University of Denver; Denver; Colorado; December 1998.

[117] A. R. Chughtai; D. M. Smith and M. Kumosa; Chemical analysis of a field-failed composite suspension insulator; Compos Sci Technol.; 58; 1641-1647; 1998.

[118] D. Armentrout; T. Ely; S. Carpenter and M. Kumosa; An investigation of brittle fracture in composite materials used for high voltage insulators; J Acous Emission; 16(1-4); S10-S18; 1998.

[119] T. S. McQuarrie; Improved dielectric and brittle fracture resistant core rods for nonceramic insulators; Insulator World Congress on Insulator Technologies for the Year 2000 and Beyond, Barcelona; Spain; 14-17; 1999.

[120] S. H. Carpenter and M. Kumosa; An investigation of brittle fracture of composite insulator rods in an acidic environment with static or cyclic loading; J Mater Sci.; 35(17); 4465-4476; 2000.

[121] C. de Tourreil; L. Pargamin; G. Thevenet and S. Prat; Brittle fracture of composite insulators: Why and how they occur; Power Engineering Society Summer Meeting 2000; 4; 2569-2574; 2000.

[122] M. Kumosa et al.; Fracture analysis of composite insulators; EPRI; Palo Alto; CA; 1006293; 2001.

[123] J. T. Burnham; T. Baker; A. Bernstorf; C. de Tourreil; J. M. George; R. Gorur; R. Hartings; B. Hill; A. Jagtiani; T. S. McQuarrie; D. Mitchell; D. Ruff; H. Schneider; D. 
Shaffner; J. Yu and J. Varner; IEEE Task Force Report: Brittle Fracture in Non-Ceramic Insulators; IEEE Trans Power Deliv.; ;17(3); 2002.

[124] M. Kumosa et al.; Failure analysis of composite high voltage insulators. EPRI; Palo Alto; CA 1007464; 2002.

[125] M. Kumosa; Y. Han and L. Kumosa; Analyses of composite insulators with crimped end-fittings; part I-non-linear finite element computations; Compos Sci Technol.; 62;1191-1207; 2002.

[126] M. Kumosa; D. Armentrout; L. Kumosa; Y. Han and S. H. Carpenter; Analyses of composite insulators with crimped end-fittings; part II-suitable crimping conditions. Compos Sci Technol.; 62; 1209-1221; 2002.

[127] D. Armentrout; M. Kumosa and T. S. McQuarrie; Boron free fibres for prevention of acid induced brittle fracture of composite insulator GRP rods; IEEE Trans Power Deliv.; 18(3); 684-693; 2003.

[128] F. F. Hanna; A. A. Yehia; I. K. Hakim; A. M. Bishai and A. L. G. Saad; Br. Polym. J.; 15; $154 ; 1983$.

[129] F. F. Hanna; K. N. Abdel-Nour and S. L. Abdel Messieh; Polym. Deg. Stab.; 35; 49; 1992.

[130] V. Mentilik; Thermochim. Acta.; 93; 353; 1985; CA 103 216292g; 1985.

[131] P. Penezek and W. Tokarski; Polymer; 16(9-10); 475; 1971; CA 76 113977m; 1971.

[132] Matsushita Electric Work Ltd.; Japan Kokai Tokkyo Koho; JP 6084 350; 1985; CA 103 88677e; 1986.

[133] Toray Industries Inc.; Japan Kokai Tokkyo Koho; JP 59119 618; 1984; CA 101 172676v; 1984.

[134] K. Shigeru; Jpn. Kokai Tokkyo Koho; JP 2002245856; 6pp; 2002.

[135] O. Kenji; Jpn. Kokai Tokkyo Koho; JP 2002088127; 4pp; 2002.

[136] M. Testsu; M. Yuichiro; K. Takao and Y. Minoru; Jpn. Kokai Tokkyo Koho; JP 2001131397; 11pp; 2001.

[137] K. Shigeru; Jpn. Kokai Tokkyo Koho; JP 2000154312; 5pp; 2000.

[138] W. Shoichi; N. Seiichi; K. Koichi and U. Tomoyuki; Jpn. Kokai Tokkyo Koho; JP 11140287; 8pp; 1999.

[139] O. Yasuo; Jpn. Kokai Tokkyo Koho; JP 10095910; 10pp; 1998.

[140] O. Toshishide; Jpn. Kokai Tokkyo Koho; JP 2002294057; 7pp; 2002.

[141] O. Kenji; Jpn. Kokai Tokkyo Koho; JP 2002088127; 4pp; 2002.

[142] A. Zheglova; Fachtagung Ueber Verarbeitung Und Anwendung Von Polymeren, $17^{\text {th }}$ Chemnitz; Germany; 701-706; 2001.

[143] B. Jalajakumari; K. G. K. Warrier; K. G. Satyanarayana and C. Pavithran; Journal of Reinforced Plastics and Composites; 7(5); 402-412; 1988.

[144] R. Schmidtschneider; Gummi; Fasern; Knustst; 47; 304; 1994; CA. 123 58005e; 1995.

[145] Toho Belson Co. Ltd.; Jpn. Pat.; JP 82 49,612; 1982; CA. 97 56696b; 1982.

[146] S. Murakami; M. Takezawa; M. Miyazaki; Y. Ishida; and H. Inone; Jpn. Pat. JP 62 292,839; 1987; CA 108 187922r; 1988.

[147] W. Tao; H. Yao; Y. Chu; T.Chao and S. Li; KO Fen Tzu Tung Hsun; 6(5); 337; 1964; CA 64 6825g; 1966. 
[148] L. T. Kravchenko; and Y. Y. Zherdev; Plasticheskic Massy; 4; 47; 1964; CA 64 2419d; 1966.

[149] E. Shiratsuchi; I. Ogura; S. Kobayashi and K. Tomioka; Jpn. Pat. JP 72 16,657; 1973; CA 77 165590V; 1973.

[150] G. S. Springer and S. W. Tsai; Thermal conductivities of unidirectional materials. J Compos Mater.; I(2); 166-173; 1967.

[151] J. Halpin and S. W. Tsai; Effects of environmental factors of composite materials; AFML-TR; 67-423; 57-64; 1969.

[152] C. H. Shen and G. S. Springer; Moisture absorption and desorption of composite materials; J Compos Mater.; 10; 2-20; 1976.

[153] G. S. Springer; Moisture content of composites under transient conditions; J Compos Mater.; 10; 107; 1976.

[154] C. D. Shirell and J. Halpin; Moisture absorption and desorption in epoxy composite laminates; Composite Materials: Testing and Design (Fourth Conference); ASTM STP $617 ; 514-28 ; 1977$.

[155] K. Kondo and T. Taki; Moisture diffusivity of unidirectional composites; Environmental effects on composite materials; Lancaster; PA: Technomic Publishing Company; 1 ; 288-299; 1981.

[156] G. S. Springer; editor. Environmental effects on composite materials; Lancaster; PA: Technomic Publishing Company; 1; 1981.

[157] G. S. Springer; editor. Environmental effects on composite materials; Lancaster; PA: Technomic Publishing Company; 2; 1984.

[158] M. Woo and M. R. Piggott; J Compos Technol Res.; 10; 20-24; 1988.

[159] ASTM standard D5229/D5229M-92; Standard test methodology for moisture absorption properties and equilibrium conditioning of polymer matrix composite materials. American Society for Testing and Materials; 1992.

[160] L. R. Bao and A. F. Yee; Moisture diffusion and hygrothermal aging in bismaleimide matrix carbon fibre composites: part I-uni-weave composites; Compos Sci Technol.; 62; 2099-2110; 2002.

[161] H. G. Carter and K. G. Kibler; Langmuir-type model for anomalous moisture diffusion in composite resins; J Compos Mater. 12; 118-131; 1978.

[162] M. E. Gurtin and C. Yatomi; On a model for two phase diffusion in composite materials; J Compos Mater.; 13; 126-130; 1979.

[163] J. P. Lucas and J. Zhou; The effects of sorbed moisture on resin-matrix composites; JOM;37-40; 1993.

[164] L. W. Cai and Y. Weitsman; Non-fickian moisture diffusion in polymeric composites; J Compos Mater.; 28; 130-154; 1994.

[165] J. Zhou and J. P. Lucas; The effects of a water environment on anomalous absorption behavior in graphite/epoxy composites; Compos Sci Technol.; 1995.

[166] M. W. Ranney; S. E. Berger and J. G. Marsden; 27 th Ann. Technol. Conf. Reinfor. Plastics/Compos.; Inst. Soc. Plas. Ind. 21D; 1-22; 1972.

[167] ASTM D -495, Test Method for High- Voltage, Low-Current, Dry Arc Resistance of Solid Electrical Insulation, 1984. 
[168] ASTM D-257, Tests for DC Resistance or Conductance of Insulating Materials, 1978.

[169] B. Z. Dholakiya et. al., Kaolin filled unsaturated polyester resin based electrical laminates in Chemical Engineering World, Vol. 40(7), 80-85, July 2000.

[170] B. Z. Dholakiya et. al., Reinforced polymer composites based on acrylic modified unsaturated polyester resin-mica having improved electrical and mechanical properties in Ultra Science Vol. 19(3), 397-404, 2007.

[171] O.C.Zaske, S.H.Goodman; .Unsaturated Polyester, Vinyl Ester Resins., In S.H.Goodman; (Ed.); .Handbook of Thermoset Plastics., 2nd Ed.; Noyes Publication, Westwood, 97, (1998).

[172] H.V.Boenig; .Unsaturated Polyesters., Structure and Properties, Elsevier, Amsterdam, (1964).

[173] B.Parkyn; F.Lamb, B.V.Clinton; Polyesters, Unsaturated Polyesters and Polyester Plasticizers, Elsevier, New York, 2, (1967).

[174] A.Saamanen; Methods to Control Styrene Exposure in the Reinforced Plastics Industry, Doctoral Thesis, University of Kuopio, 29 August, (1998).

[175] W.Shoichi, N.Seiichi, K.Koicji, U.Tomoyuki; Jpn Kokai Tokkyo Koho, JP 11140287; 8 (1999).

[176] Isao Watanabea, Shin-ichi Sakaib; Environment International, 29, 665-682 (2003).

[177] Cynthia A.de Wit; Chemosphere, 46, 583-624 (2002).

[178] Synthesis, Characterization and Glass reinforced Composites of Low Styrene Emission Unsaturated Polyester Resin having improved fire resistance and mechanical properties in Macromolecule, MMAIJ, 3(4), 169-175, 2007. 